Tian, Q., Xiao, Q.,Sun, Y., Hu, H., Flores, P., Coupling dynamics of a geared multibody system supported by Elastohydrodynamic lubricated cylindrical joints. Multibody System Dynamics, Vol. 33, pp. 259-284, 2015

\title{
Coupling dynamics of a geared multibody system supported by ElastoHydroDynamic lubricated cylindrical joints
}

By

Qiang Tian ${ }^{1 *}$, Qianfei Xiao ${ }^{1}$, Yanlei Sun ${ }^{1}$, Haiyan $\mathrm{Hu}^{1}$, Hui Liu ${ }^{2}$, Paulo Flores ${ }^{3}$

${ }^{1}$ Ministry of Education (MOE) Key Laboratory of Dynamics and Control of Flight Vehicle, School of Aerospace Engineering, Beijing Institute of Technology, Beijing 100081, China.

*E-mail address: tianqiang_hust@aliyun.com

*Tel (Fax): +86-010-68912731

${ }^{2}$ School of Mechanical Engineering, Beijing Institute of Technology, Beijing 100081, China.

${ }^{3}$ Department of Mechanical Engineering, University of Minho

Campus de Azurém, 4800-058 Guimarães, Portugal

E-mail: pflores@dem.uminho.pt

*Author to whom all correspondence should be addressed 


\begin{abstract}
A comprehensive computational methodology to study the coupling dynamics of a geared multibody system supported by ElastoHydroDynamic (EHD) lubricated cylindrical joints is proposed throughout this work. The geared multibody system is described by using the Absolute-Coordinate-Based (ACB) method that combines the Natural Coordinate Formulation (NCF) describing rigid bodies and the Absolute Nodal Coordinate Formulation (ANCF) characterizing the flexible bodies. Based on the finite-short bearing approach, the EHD lubrication condition for the cylindrical joints supporting the geared system is considered here. The lubrication forces developed at the cylindrical joints are obtained by solving the Reynolds' equation via the finite difference method. For the evaluation of the normal contact forces of gear pair along the Line Of Action (LOA), the time-varying mesh stiffness, mesh damping and Static Transmission Error (STE) are utilized. The time-varying mesh stiffness is calculated by using the Chaari's methodology. The forces of sliding friction along the Off-Line-Of-Action (OLOA) are computed by using the Coulomb friction models with a time-varying coefficient of friction under the EHD lubrication condition of gear teeth. Finally, two numerical examples of application are presented to demonstrate and validate the proposed methodology.
\end{abstract}

Keywords: Geared multibody system, Absolute Nodal Coordinate Formulation (ANCF), time-varying meshing stiffness, sliding frictional force, ElastoHydroDynamic (EHD) lubrication 


\section{Introduction}

The geared mechanical systems have been widely used in many industrial fields, such as the vehicle-geared reducer, the geared rotors, which are often supported by lubricated bearings. For the convenience of dynamic analysis, the lubricated bearings are in general considered as the lubricated cylindrical joints at the ends of transmission shafts. In order to extend the service life of gear teeth, the lubricant is also introduced into the clearance of gear teeth. Thus, it is clear that an actual geared system supported by lubricated cylindrical joints may exhibit very complex coupling dynamic features due to the part flexibility and the lubricant phenomena. Therefore, a correct and deep understanding of the coupling dynamics of this type of mechanical systems is of primordial importance to control the reliability and performance of the system, as well as to ensure the smooth and safe operate conditions.

In the field of multibody methodologies, the dynamics of mechanical systems with the clearance and lubricated effects of joints considered has attracted much attention over the past few decades [1-6]. The range of applications of most of these works, however, is somewhat limited because they have focused on the general multibody systems without including gear bodies. Tian et al. [7], Flores and Lankarani [8], Stefanelli et al. [9], Brutti et al. [10] and Liu et al. [11] are among the very few researchers who performed the dynamic analysis of spatial cylindrical joint with or without lubrication conditions. In these works, the lubricant effects were studied under the assumptions of either an infinitely-short or an infinitely-long journal/bearing for the cylindrical joint. Therefore, it is possible to derive the analytical expressions to describe the lubricant pressures by neglecting some terms in the Reynolds' equation according to the HydroDynamic (HD) theory [12]. Once the lubricant pressures are known, the corresponding analytical equations for the lubrication forces can be obtained by using the Gümbel's conditions or Sommerfeld's conditions according to HD approach [13]. With the advent of Computational Fluid Dynamics (CFD) and Fluid-Structure Interaction (FSI) techniques, the dynamic analysis of a multibody system with lubricated bearings can exhibit the complex 
behavior due to the bearing flexibility. It is not surprising that the subject of EHD analysis for lubricated joints has deserved the attention of significant researchers in the field of tribology [14, 15]. For instance, Liu et al. [16], Shenoy et al. [17] and Attia et al. [18] performed the EHD analysis for the lubricated high-speed rotor-bearing systems. Their numerical results suggested that the local bearing deformations expand the pressure space in the clearance and, hence, increase the minimal film thickness. More recently, Slim et al. [19] comparatively studied the acoustic and vibrational behaviors of oil lubricated journal bearings by using the HD and EHD approaches. They showed that the sound pressure level of the bearing is significantly influenced by the flexibility of bearing liner, and the bearing noise decreases due to the EHD lubrication since the film thickness is larger than that of HD lubrication. Tian and his co-workers [20] proposed a new EHD lubricated cylindrical model developed under the framework of flexible multibody formulation. The lubricated cylindrical joints in a flexible multibody system are described by using Absolute Coordinate Based (ACB) method, which combines the Natural Coordinate Formulation (NCF) [21] for rigid bodies and the Absolute Nodal Coordinate Formulation (ANCF) [22] for flexible bodies. The ANCF initially presented by Shabana [22], has become a benchmark in the development of dynamics of flexible multibody systems $[23,24]$.

Over the past few decades, a good number of theoretical and experimental studies have been proposed to model and analyze geared mechanisms, especially geared rotor systems [25]. Kahraman and Singh [26, 27] demonstrated that the gear backlash and time-varying mesh stiffness can significantly affect the geared mechanism response. Theodossiades and Natsiavas [28] investigated the dynamic responses and stability characteristics of a planar rotor system interconnected with gear pairs and supported by oil journal bearings. In their study, the gear mesh stiffness in a time Fourier series form was utilized and the gear backlash was modeled as a piecewise linear function. The flexibility of the interconnecting shafts was also modeled by employing the component mode synthesis method. Shiau et al. [29] presented a hybrid method of the finite element method and the general polynomial 
expansion method to study the dynamic characteristics of geared rotor systems. Fernandez del Rincon and his co-authors [30] presented an advanced model for the analysis of contact forces and deformations in spur gear transmissions. They formulated the deformation at each gear contact point as a combination of a global term and a local term. Rao et al. [31] studied the lateral response of a geared-rotor system with flexible shafts under torsional excitation, in which the flexible shafts were modeled as a 2-node shaft element with 10 degrees-of-freedom (DOFs). However, a simple linear spring-damper approach was utilized to model the contact interaction between each gear pair, in which the spring stiffness was assumed to be constant [32]. Baguet and Jacquenot [33] investigated the coupling dynamics of a hydrodynamic lubricated planar gear-shaft-bearing system. The flexible shafts were modeled by using the classical 2-node finite elements with 6 DOFs per node for bending, torsional and axial displacements. The nonlinear dynamic responses of a planar gear-bearing system subject to the nonlinear suspension effects, nonlinear oil-film force and nonlinear gear mesh force have also been the object of intense research by Wan and Jian [34]. Their outcomes showed that the system exhibits a varied range of periodic, sub-harmonic and chaotic behaviors. It should be pointed out that the studies mentioned above on the geared mechanisms are only valid for the HD theory and for planar cases. In addition, the joint constraint conditions have not yet been addressed and, therefore, the final derived equations of motion are expressed by a set of Ordinary Differential Equations (ODE). Consequently, many important joint dynamic features of geared mechanisms can not be considered, such as the joint reaction forces, which play a key role, for instance, in the design of control scheme of the geared system. Using the modal superposition method, Vinayak and Singh [35] extended the multibody dynamics modeling strategy for rigid gears to include compliant gear bodies in multiple-mesh transmission system. Wang et al. [36] also investigated the coupling dynamics of the geared mechanism based on the theoretic framework of multibody system dynamics. Chang [37] considered the coupling dynamics of a spatial quick-return mechanism with a flexible geared rotor, in which the flexible multibody model of the geared mechanism was established by using the 
Hamilton's principle and the flexible rods were model by using the modal shape function based on the Timoshenko-beam theory.

The gear mesh action is generally characterized by the combination of rolling and sliding under EHD lubrication conditions. The forces of sliding friction developed between the gear tooth surfaces are believed to be one of the major sources of gear vibration and noise, especially under high-torque and low-speed conditions, because the rolling resistance is considerably smaller than the sliding resistance [38, 39]. Many simple and empirical friction force models have been incorporated in various forms in previous investigations, such as the Coulomb model with a constant coefficient of friction $[40,41]$. Nevertheless, the tribological conditions of the contact gear tooth surfaces can change periodically due to time-varying mesh properties and also due to lubricant film thickness as the gears are rolling. Hence, the value of the coefficient of friction also varies instantaneously with the spatial position of teeth and the direction of friction force changes at the meshing point. With the intent of predicting the traction force generated by the lubricant, the EHD theory has been extensively utilized to explain the interface friction in gears. $\mathrm{Xu}$ et al. [42, 43] proposed a novel friction model that uses a friction coefficient expression obtained from a large number of EHD lubrication analyses covering typical ranges of fundamental parameters associated with gear teeth, such as the surface roughness, geometry and lubricant action. He et al. [44] studied the influence of different sliding friction force models on the dynamic response of a pair of spur gears, where the predicted friction force was validated from measurement data.

In this paper, based on the previous studies on the mathematical mesh models for lubricated gear pairs and the dynamics of flexible multibody mechanisms with lubricated joints, the coupling dynamics of geared multibody mechanisms with EHD lubrication conditions has been investigated. The remaining of the paper is organized as follows. In Section 2, the multibody model of a classic geared rotor based on ACB method is briefly described. The flexible bodies including the flexible bearings and shafts are modeled by using the finite elements of ANCF. In turn, the rigid bodies including the short journal in the bearing and the gears are modeled by using NCF. In 
Section 3, the mathematical models of normal contact forces of gear teeth along LOA and forces of sliding friction along OLOA are described. In the case of EHD lubricated cylindrical joints, the lubrication pressures are evaluated by using the finite difference method. The time-varying gear mesh stiffness, time-varying gear mesh damping and time-varying static transmission error are also taken into account. Section 4 presents an efficient computational algorithm to solve the set of dynamic equations for the geared multibody system. In Section 5, a parametric study of a geared rotor-bearing multibody system supported by 4 EHD lubricated cylindrical joints is performed with the intent to validate the proposed approach. The influence of the mathematical model parameters and gear design parameters on the dynamic responses of the system is carefully studied. Then, the coupling dynamics of a quick-return mechanism driven by a lubricated geared rotor is also analyzed and discussed. Finally, in Section 6 the main conclusions of this study and some future perspectives are addressed.

\section{Multibody model of a geared rotor based on ACB method}

Figure 1 shows the configuration of a classical geared rotor. In the present study, the Absolute Coordinate Based (ACB) method, that combines the Natural Coordinate Formulation (NCF) [21] describing rigid bodies and the Absolute Nodal Coordinate Formulation (ANCF) [22] characterizing flexible bodies, is utilized to represent the multibody model of the geared system depicted in Fig. 1. This method has found many successful applications from the computational point of view since the mass matrix for the whole rigid-flexible system keeps constant and the system constraint conditions can be easily simplified [7, 20, 45, 46].

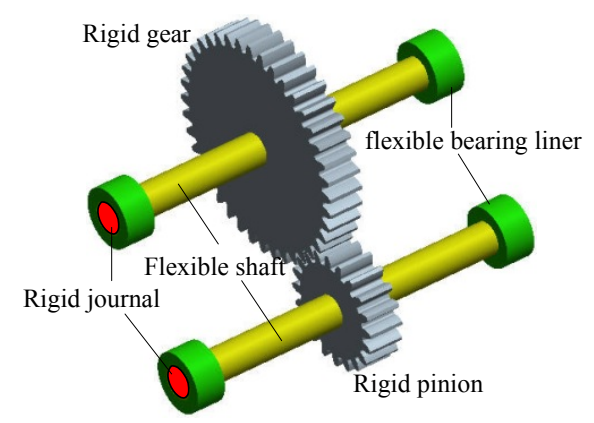

Fig. 1 Rigid-flexible mulitbody model of a geared rotor 
In Fig. 1, the rigid gear and pinion are installed on 2 flexible shafts, which are modeled by using NCF. According to the work by García De Jalón and Bayo [21] the motion of a rigid body can be defined through 2 position vectors of 2 basic points and 2 unit vectors, as it is illustrated in Fig. 2. Thus, for instance, the generalized coordinates defined in the global coordinate system for the rigid gear can be expressed as $\left[\begin{array}{llll}\mathbf{r}_{P_{1}}{ }^{T} & \mathbf{r}_{P_{2}}{ }^{T} & \zeta_{p}{ }^{T} & \boldsymbol{\eta}_{p}{ }^{T}\end{array}\right]^{T}$. Therefore, a rigid body can be described via 12 generalized coordinates of NCF, which indicates that there still exist 6 constraint equations for the rigid body itself. As mentioned before, the NCF describing rigid bodies leads to a constant mass matrix for a rigid multibody system. The fundamental circles to define the gear pair are represented in Fig. 2. It can be observed that the pitch circles are tangent with each other at the pitch point $P$.

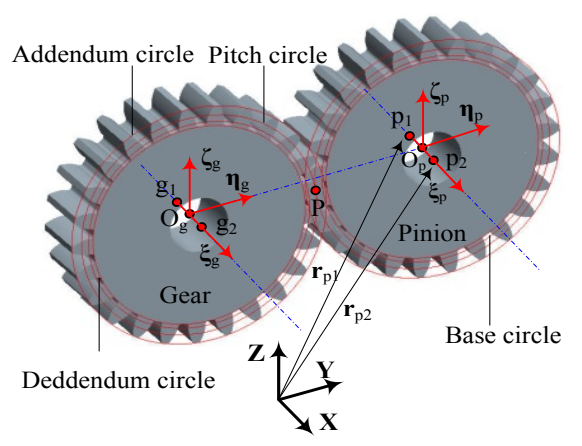

Fig. 2 A pair of spur gears described by NCF

In the present study, the flexible shafts shown in Fig. 1 are meshed by using the fully parameterized beam elements of ANCF [47, 48]. As shown in Fig. 3, the 2-node beam element with circular cross-section is defined as $\mathbf{e}=\left[\mathbf{r}_{i}, \mathbf{r}_{i, x}, \mathbf{r}_{i, y}, \mathbf{r}_{i, z}, \mathbf{r}_{j}, \mathbf{r}_{j, x}, \mathbf{r}_{j, y}, \mathbf{r}_{j, z}\right]^{T}$, includng 24 global nodal coordinates. The ANCF also leads to a constant mass matrix for a flexible multibody system since all the nodal coordinates of ANCF elements are defined in a global coordinate system. Another special feature associated with ANCF elements is that it employs the mathematical definition of the slopes, instead of the rotational coordinates, to describe both rotation and deformation of a finite element. Thus, the ANCF originally proposed by Shabana [22], as an accurate, non-incremental finite element method to 
accurately deal with the dynamics of flexible multibody systems subject to both large overall rotation and large deformation, has become a benchmark in the development of dynamics of flexible multibody systems [23, 24]. The bending and torsional behaviors of ANCF element have been validated in the work by Liu et al. [46]. Therefore, the bending-torsional coupled behaviors of a flexible gear shaft can be accurately predicted.

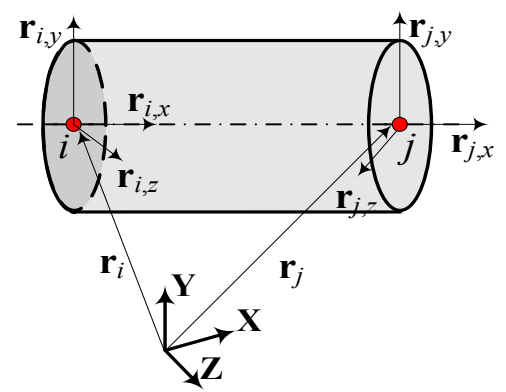

Fig. 3 A fully parameterized beam elements with circular cross-section of ANCF

Finally, for the 4 lubricated cylindrical joints supporting the flexible shafts, the NCF is utilized to model the rigid journal in the bearing liner, and the 20 -node hexahedral elements of ANCF are used to model the flexible bearing liner. As shown in Fig. $4, \xi-\eta-\zeta$ denotes the local coordinate system of bearing with its origin at the mass center of bearing $O_{b}$. The readers can also find the detail description of 20-node hexahedral element of ANCF in the work by Tian et al. [20].

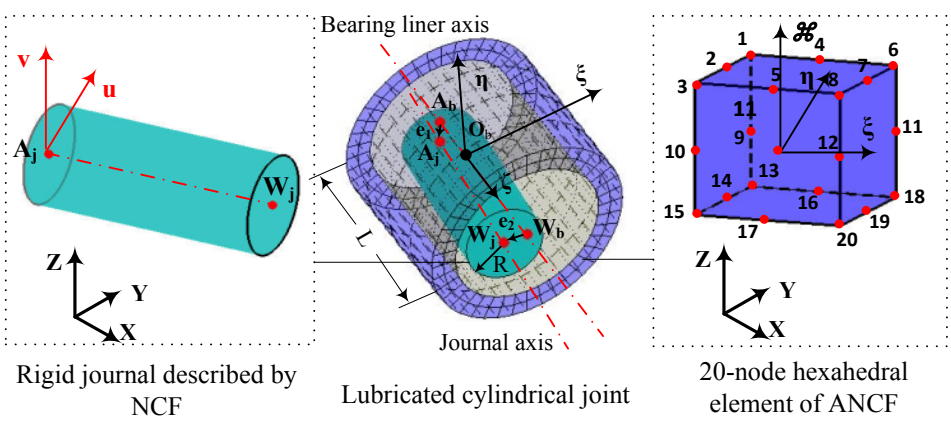

Fig. 4. Lubricated cylindrical joint described by the ACB method

\section{Mathematical models of gear mesh forces and lubrication forces}




\subsection{Mathematical models of contact forces of gear teeth}

Figure 5 depicts the potential meshing pattern of a pair of spur gears. The Line-Of-Action (LOA) connects points $N_{1}$ and $N_{2}$. The Off-Line-Of-Action (OLOA) is perpendicular to LOA. $r_{b g}$ and $r_{b g}$ denote the gear and pinion base radius, respectively, which can be determined from the number of teeth, the pressure angle $\alpha$ and the gear module. $\omega_{p}$ and $\omega_{g}$ are the averaged rotational speeds of pinion and gear, respectively. $\mathbf{N}_{A}$ and $\mathbf{N}_{C}$ are the normal contact forces along the LOA direction at the contact points $A$ and $C$, while $\mathbf{f}_{A}$ and $\mathbf{f}_{C}$ represent the friction forces along the OLOA direction at the contact points $A$ and $C$, respectively.

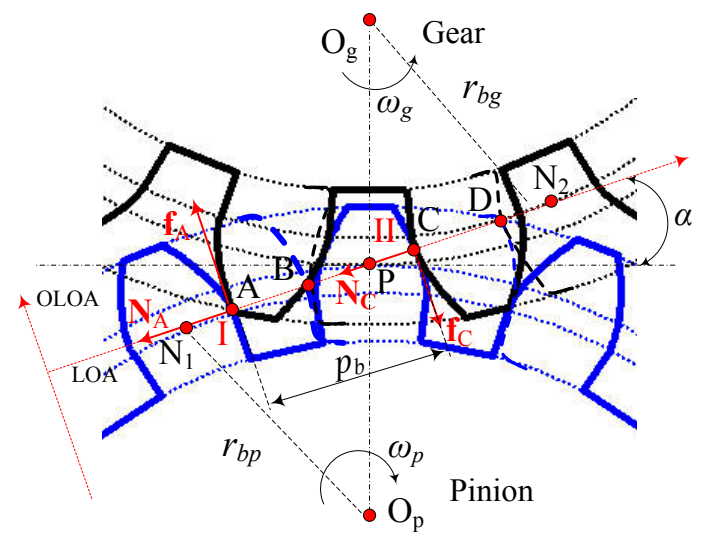

Fig. 5 Potential meshing pattern of a pair of spur gears

At the beginning $t=0$ of a meshing cycle, a gear pair I (tooth pair rolling along line $A C$ ) enters into contact at point $A$. At the same instant, another pair II (tooth pair rolling along line $C D$ ) contacts at point $C$. As the pinion rolls, when the meshing point of pair I reaches point $B$ at time $t=t_{b}$, the pair II leaves the contact. At this instant, there is also a sudden reduction in the meshing stiffness of the system. Between points $B$ and $C$, there is only a single tooth pair in contact. Thus, the points $B$ and $C$ are often called the Lowest Point of Single Tooth Contact (LPSTC) and the Highest Point of Single Tooth Contact (HPSTC), respectively [44]. When the meshing point of pair I passes through the pitch point $P$ at instant $t=t_{p}$, the relative sliding velocity at the meshing point reverses and results in a sharp reversal of friction force direction. At this instant, a sharply impulsive excitation is generated. When the meshing point of 
pair I passes through point $C$ at instant $t=t_{c}$, pair I is re-defined as pair II and the incoming meshing tooth pair at meshing point $A$ is re-defined as pair I. Thus, at the instant $t=t_{c}$, the mesh cycle is finished. As shown in Fig. 5, the length of $A C$ is defined as one based pitch $p_{b}$. The total mesh cycle time $t_{c}$, and key mesh events time $t_{b}$ and $t_{p}$ can be obtained as following

$$
t_{c}=\frac{p_{b}}{\omega_{p} r_{b p}}=\frac{2 \pi}{Z_{p} \omega_{p}}, t_{b}=\frac{L_{A B}}{p_{b}} t_{c}, t_{p}=\frac{L_{A P}}{p_{b}} t_{c} .
$$

where $Z_{p}$ is the number of gear teeth. $L_{A B}$ and $L_{A P}$ denote the length of line $A B$ and line $A P$, respectively, and can be calculated as

$$
L_{A P}=\frac{p_{b} \varepsilon}{2}, L_{A B}=p_{b}(\varepsilon-1),
$$

in which $\varepsilon$ denotes the gear pair contact ratio, and can be determined by the design parameters of gear and pinion.

Due to the periodicity of the meshing events, the meshing time duration for single-tooth engagement can be evaluated as

$$
t_{s}=t_{c}(2-\varepsilon)
$$

Similarly, the time duration for double-tooth engagement can be determined as

$$
t_{d}=t_{c}(\varepsilon-1)
$$

In order to evaluate the normal contact forces, along the LOA direction, at the contact points, the mechanical model for a single-tooth engagement state is usually simplified as a classical spring-damper system as illustrated in Fig. 6 [25-27]. The coordinate system, shown in Fig. 6, is defined in the global coordinate system by using NCF. Each gear is represented by a rigid disk coupled by a time-varying mesh stiffness $k(t)$, a mesh damping $c(t)$ and a static transmission error $e(t) . T_{p}$ and $T_{g}$ denote the driving torque and load torque, respectively. 


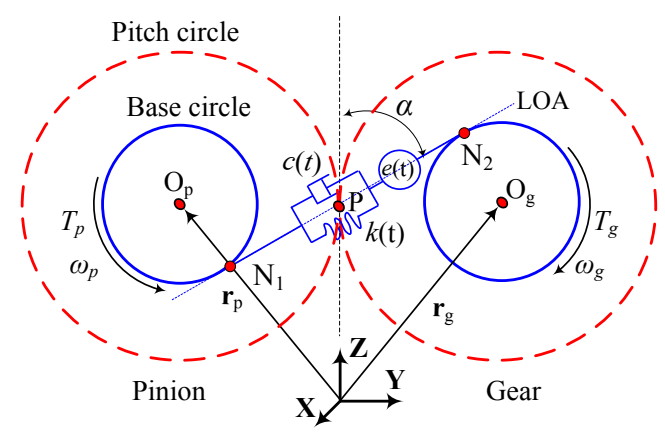

Fig. 6 Schematic view of the normal contact force along LOA in a spur gear pair

The mesh stiffness is periodic with the mesh frequency and numerous approaches have been employed to determine the mesh stiffness. The Finite Element Method (FEM) is one of the most popular employed techniques [49]. However, this approach tends to be computationally intensive, since very dense mesh grid is needed to achieve accurate results. In turn, analytical models are usually more efficient than FEM, and in some cases they may yield satisfactory tooth mesh stiffness results [50-55]. Recently, Chaari and his co-authors, based on previous works [50, 53, 56], proposed a new combined analytical model to evaluate the mesh stiffness [57-59]. Their studies indicated that the mesh stiffness results calculated by using their model are in a very good agreement with the results obtained via FEM.

With the purpose to determine the mesh stiffness, the gear tooth deflections should be firstly described and evaluated. According to the works by Chaari et al. [57-59], for a loaded gear tooth, the total deflection along the loading direction is composed by 3 deflections namely, the bending deflection $\delta_{b}$, the deflection $\delta_{f}$ of the fillet and foundation and the local contact and compression $\delta_{h}$. As shown in Figure 7, for a gear tooth under the action of a meshing force $F$, the bending deflection of a tooth is determined by considering it as a nonuniform cantilever beam with an effective length $L_{e}$, which is divided into $n$ segments. According to the Weber's tooth bending equation [50], the bending deflection $\delta_{b}$ can be expressed as

$$
\delta_{b}(t)=\frac{F \cos ^{2} \alpha}{E} \sum_{i=1}^{n} e_{i}(t)\left[\frac{l_{i}(t)^{2}-l_{i}(t) e_{i}(t)+\frac{1}{3} e_{i}(t)^{2}}{\bar{I}_{i}(t)}+\frac{2.4(1+v)+\tan ^{2} \alpha}{\bar{A}_{i}(t)}\right]
$$


where $\frac{1}{\bar{I}_{i}}=\left(\frac{1}{I_{i}}+\frac{1}{I_{i+1}}\right) / 2$ and $\frac{1}{\bar{A}_{i}}=\left(\frac{1}{A_{i}}+\frac{1}{A_{i+1}}\right) / 2 . I_{i}$ denotes the area moment of inertia of the $i$-th tooth cross segment $S_{i}, A_{i}$ is the area of the $i$-th tooth cross section, $v$ represents the Poisson's ratio of the gear tooth material, $\alpha$ is the gear pressure angle, $e_{i}$ is the thickness of a segment and $e_{i}=L_{e} / n . l_{i}$ is the distance between the load point and the $i$-th tooth cross segment. These parameters are represented in Fig. 7. Therefore, the bending stiffness of the tooth can be evaluated by

$$
k_{f}(t)=F / \delta_{b}(t) .
$$

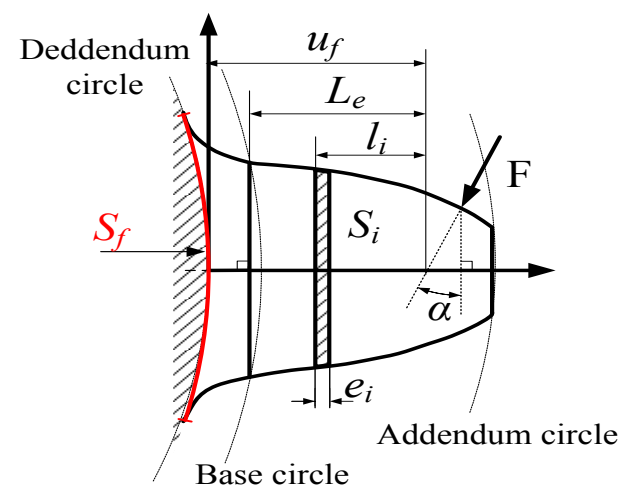

Fig. 7. Modeling of a spur gear tooth as a nonuniform cantilever beam

Furthermore, according to the work by Sainsot et al. [54], the deflection of the fillet and foundation $\delta_{f}$ yields

$$
\delta_{f}(t)=\frac{F \cos ^{2} \alpha}{E b}\left[L^{*}\left(\frac{u_{f}(t)}{S_{f}}\right)^{2}+M^{*}\left(\frac{u_{f}(t)}{S_{f}}\right)+P^{*}\left(1+Q^{*} \tan ^{2} \alpha\right)\right]
$$

where $b$ denotes the face width of a gear tooth, $S_{f}$ and $u_{f}$ are the geometrical parameters of a gear. The coefficients $L^{*}, M^{*}, P^{*}, Q^{*}$ can be approached by the polynomial functions,

$$
X_{i}\left(h, \theta_{f}\right)=A_{i} / \theta_{f}^{2}+B_{i} h^{2}+C_{i} h / \theta_{f}+D_{i} / \theta_{f}+E_{i} h+F_{i}, i=1,2,3,4 .,
$$

where $X_{1}=L^{*}, X_{2}=M^{*}, X_{3}=P *$ and $X_{4}=M^{*}$. The definitions of the gear geometrical parameters ( $h$ and $\theta_{f}$ ) and the constants $A_{i}, B_{i}, C_{i}, D_{i}, E_{i}$ and $F_{i}$ can be found in the work by Sainsot et al. [54]. 
The corresponding fillet-foundation stiffness satisfies

$$
k_{f}(t)=\frac{F}{\delta_{f}(t)} .
$$

Finally, the third deflection component, the local contact and compression deformation $\delta_{c}$ can be calculated by using a linearized Hertzian contact model with constant stiffness proposed by Yang and Sun [56], that is

$$
\delta_{h}=\frac{F}{k_{h}},
$$

where $k_{h}$ denotes the constant contact stiffness and yields

$$
k_{h}=\frac{\pi E b}{4\left(1-v^{2}\right)},
$$

in which $v$ and $E$ represent Possion's ratio and the Young's modulus of gear material, respectively. Thus, for a pair of teeth in contact the mesh stiffness $k$ can be written as

$$
k(t)=1 /\left(\frac{1}{k_{b p}(t)}+\frac{1}{k_{b g}(t)}+\frac{1}{k_{f p}(t)}+\frac{1}{k_{f g}(t)}+\frac{1}{k_{h}}\right),
$$

where the symbols " $p$ " and " $g$ " denote the pinion and the gear, respectively.

Based on Fig. 5, the relation between the mesh stiffness of tooth pair I and the mesh stiffness of tooth pair II at an instant can be expressed as

$$
k_{I}\left(t+t_{c}\right)=k_{I I}(t) .
$$

The final time-varying mesh stiffness function can be expressed by

$$
k(t)=k_{I}(t)+k_{I I}(t)
$$

In Fig. $6 e(t)$ denotes the Static Transmission Error (STE), resulting from geometrical errors in the gear tooth profile and spacing. This error is a periodic function of the rigid-body rotation of the gears. The STE can be assumed to be sinusoidal function with tooth passing frequency $[37,60]$ as

$$
e(t)=e_{r} \sin \left(\omega_{p} Z_{p} t\right)=e_{r} \sin \left(\omega_{g} Z_{g} t\right),
$$

where $e_{r}$ is the amplitude of the STE. Chang [37] found that the transmission error can induce high frequency oscillations in a gear system and that the severe oscillations will be generated if large amplitude is adopted. It must be noted that in the present 
study the influence of the static transmission on the mesh stiffness is not considered.

Furthermore, the viscous mesh damping coefficient $c$ can be calculated by [49, 61]

$$
c(t)=2 \zeta \sqrt{k(t) m_{e q}},
$$

where $\zeta$ is the damping ratio. The equivalent mass $m_{e q}$ is defined as

$$
m_{e q}=\frac{I_{p} I_{g}}{r_{p b}^{2} I_{g}+r_{g b}^{2} I_{p}},
$$

where $I_{p}$ and $I_{g}$ are the mass moments of inertia of pinion and gear, respectively.

Once the time-varying mesh stiffness function, viscous mesh damping coefficient and the static transmission error are obtained, with regards to Fig. 6, the magnitude of the instant normal contact force $N$ of a gear tooth along the LOA direction can be calculated by

$$
N(t)=k(t)[\delta(t)-e(t)]+c(t)[\delta(t)-d(t)],
$$

where $\delta$ is defined as the Dynamic Transmission Error (DTE) of the system, and given by

$$
\delta=r_{b p} \omega_{p} t-r_{b g} \omega_{g} t
$$

Once the normal contact forces along LOA are in hand, the corresponding torques that should be imposed at the gear and pinion centers of mass can be easily evaluated.

The sliding motion on the gear tooth surface causes frictional forces along the OLOA direction, as it is observed in Fig. 5. In general, researchers [39-41] have modeled the sliding friction phenomenon by using Coulomb's law with a constant friction coefficient. According to Coulomb's law of dry friction, the magnitude of friction force $(f)$ is proportional to the normal contact force along the LOA direction as $f(t)=\mu|\mathbf{N}(t)|$. The frictional coefficient $\mu$ can be calculated by [44]

$$
\mu=\mu_{\text {avg }} \operatorname{sgn}\left[\bmod \left(\omega_{p} r_{b p} t, p_{b}\right)-L_{A P}\right],
$$

where "mod" is the modulus function, "sgn" is the sign function to consider the direction of the frictional force, and $\mu_{\text {avg }}$ is a constant, while the parameter $L_{\mathrm{AP}}$ is represented in Fig. 5. 
In order to consider the EHD lubrication action in a gear pair, by using a multiple linear regression method, $\mathrm{Xu}$ et al. $[42,43]$ proposed an EHD-based approach to evaluate the coefficient of friction $\mu_{E H D}$, as follows

$$
\left\{\begin{array}{l}
\mu_{E H D}=e^{f\left(S R, P_{h}, v_{0}, S\right)} P_{h}^{b_{2}}|S R|^{b_{3}} V_{e}^{b_{6}} v_{0}^{b_{7}} R^{b_{8}} \\
f\left(S R, P_{h}, v_{0}, S,\right)=b_{1}+b_{4}|S R| P_{h} \log _{10}\left(v_{0}\right)+b_{5} e^{-|S R| P_{h} \log _{10}\left(v_{0}\right)}+b_{9} e^{S}
\end{array},\right.
$$

where $S R$ denotes the ratio of sliding velocity to lubricant entrainment velocity, $P_{h}$ is the maximal Hertzian pressure, $V_{e}$ represents the lubricant entrainment velocity, $v_{0}$ is the absolute viscosity, $S$ is the Root-Mean-Square (RMS) composite surface roughness expressed in $\mu \mathrm{m}, R$ is the effective radius of curvature at contact point, and $b_{i}(i=1-9)$ are 9 empirical constant coefficients. The following empirical coefficients suggested by $\mathrm{Xu}$ [43] for the above expressions are adopted in this study, namely $b_{1}=-8.916465, b_{2}=1.03303, b_{3}=1.036077, b_{4}=-0.354068, b_{5}=2.812084, b_{6}=-0.100601$, $b_{7}=0.752755, b_{8}=-0.390958$ and $b_{9}=0.620305$. Based on the simulation parameters in the work by $\mathrm{Xu}$ et al. [62], the friction coefficients can be determined by using the curves plotted in Fig. 8. It can be observed that with an increase of the lubricant entrainment velocity, the magnitudes of the friction coefficient will gradually decrease for the same $S R$ value. The same results have also been presented in the work by Xu et al. [42, 62].

Once the friction forces are determined, the corresponding frictional torques imposed at the gear and pinion centers of mass can be easily obtained. In the present study, the influence of above two friction coefficient models on the dynamic responses of geared multibody mechanisms is analyzed.

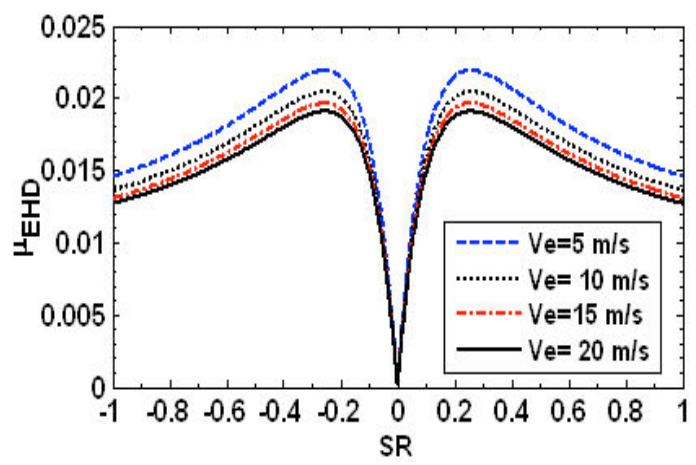

Fig. 8 Comparison of friction coefficients for $R=5 \mathrm{~mm}, P_{h}=2 \mathrm{GPa}, v_{0}=10 \mathrm{cPs}, \mathrm{S}_{\text {r.m.s. }}=0.07$ $\mu \mathrm{m}$ and various $V_{e}$ values 


\subsection{Mathematical models of EHD lubrication forces in cylindrical joints}

For the geared rotor supported by EHD lubricated cylindrical joints, the general form of the lubricant Reynolds' equation can be expressed as [12]

$$
\frac{\partial}{\partial \varphi}\left(h^{3} \frac{\partial p}{\partial \varphi}\right)+R^{2} \frac{\partial}{\partial \zeta}\left(h^{3} \frac{\partial p}{\partial \zeta}\right)=6 \tau R^{2} \omega \frac{\partial h}{\partial \varphi}+12 R^{2} \eta \frac{\partial h}{\partial t}
$$

where $p$ denotes the lubricant pressure, $\tau$ is the lubricant dynamic viscosity and $R$ is the journal radius. In order to account for the EHD lubrication condition, the lubricant film thickness can be expressed as follows

$$
h=c-\xi_{j} \cos \theta-\eta_{j} \sin \theta+\delta,
$$

where $c$ represents the radial clearance size of joint, $\delta$ denotes the elastic deformation of bearing, $\theta$ is the angular coordinate and $\left(\xi_{j}, \eta_{j}\right)$ the coordinates of an arbitrary journal cross section center defined in the coordinate system $\xi_{-} \eta-\zeta$, as shown in Fig. 4. With the purpose to evaluate the lubricant pressure and the associated bearing deformation caused by the pressure, the lubricated cylindrical joint and the pressure field can be unfolded along with the circumferential direction $(\varphi)$, as it is represented in Fig. 9

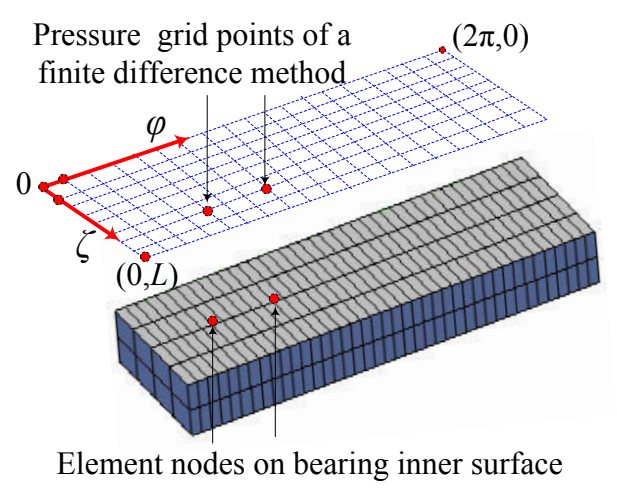

Fig. 9 EHD model of an unfolded cylindrical joint

Based on the idea described above, the lubricant pressure field can be obtained by solving Eq. (22) via the finite difference method. The detail computation procedures have been clearly described in the work by Tian et al. [20]. Once the lubricant pressures at the grid points (shown in Fig. 9) of an adopted finite-difference 
method are obtained, they can be then transformed into the corresponding generalized nodal forces for computing the elastic deformation at the corresponding nodes of the used 20-node hexahedral element of ANCF.

\section{Computational strategy}

In the present study the EHD lubricated geared mechanism is studied under the frame work of multibody system formalisms and based on the ACB method. The assembly of the finite elements of ANCF can be carried out in a similar way of classic finite element method [63]. The nodal coordinate e of a finite element of ANCF can be easily transformed into the generalized coordinate $\mathbf{q}$ of the multibody system. Therefore, the final equations of motions for a constrained geared mechanism can be expressed in a compact form as a set of Differential Algebraic Equations (DAE) with a constant mass matrix as following [64]

$$
\left\{\begin{array}{l}
\mathbf{M}+\mathbf{\Phi}_{\mathbf{q}}^{T} \lambda+\mathbf{F}(\mathbf{q})=\mathbf{Q}(\mathbf{q}, \mathbf{q} t) \\
\mathbf{\Phi}(\mathbf{q}, t)=\mathbf{0}
\end{array}\right.
$$

where the first term of the first equation represents the inertia forces, and the second term is the generalized forces associated with the constraints. At this stage, it should be noted that based on the ACB method, the mass matrix $\mathbf{M}$ always remains constant in the numerical iteration process. $\mathbf{F}(\mathbf{q})$ is the elastic forces of flexible parts which can be derived and evaluated according to the theory of continuum mechanics $[65,66]$. The term in right side of the first equation denotes the generalized external forces that act at the centers of the gear and pinion, including the components transformed from the normal contact forces $\mathbf{N}(t)$, the frictional forces $\mathbf{f}(t)$, the lubricant forces and the associated torques. The second equation in Eq. (24) represents the kinetic constraint conditions mathematically described by a set of algebraic equations.

In this study, the iterative scheme for the generalized-alpha method as proposed by Arnold and Brüls [67] is adopted to reach an optimal combination of accuracy at low-frequency and numerical damping at high-frequency. This approach has exhibited good applicability to tough problems in the works by Tian et al. [7, 20] and by Liu et 
al. [11] to study the dynamics of flexible multibody system with clearance joints. More importantly, by embedding the sparse matrix storage skills and OpenMP parallel technique into the iteration process, this computation strategy can also be utilized to simulate very complicated flexible multibody systems. The readers can also gain an insight into the efficient parallel computation strategy and interesting applications in the works by Liu et al. [66, 68].

\section{Numerical examples}

\subsection{Parametric study of a rigid spur gear pair}

With the intent to validate the mathematic models described above, the dynamic analysis of a classical spur gear pair is carried out in this section. The values of the main parameters utilized to numerically characterize the geared multibody model are extracted from the literature for a similar case [40, 41, 49], which allows to compare and validate the developed approaches. The planar gear and pinion are described by NCF approach. The mass centers of gear and pinion are fixed to the ground. Different initial pinion rotation speed $\omega_{p}$ are considered.

Based on the gear pair parameters listed in Table 1, the time-varying mesh stiffness is evaluated by using the Chaari's expressions [57-59]. According to the work by $\mathrm{He}$ et al. [49], the maximal mesh stiffness of the gear pair is set to be $k_{\max }=7.20 \mathrm{e} 8 \mathrm{~N} / \mathrm{m}$, the mean stiffness is assumed to be $k_{\text {mean }}=5.568 \mathrm{e} 8 \mathrm{~N} / \mathrm{m}$. The maximal mesh stiffness $k_{\max }$, the mean mesh stiffness $k_{\text {mean }}$ and the minimal mesh stiffness $k_{\min }$ should meet the relation [40]:

$$
k_{\text {mean }}=k_{\text {max }}(\varepsilon-1)+k_{\text {min }}(2-\varepsilon) \text {. }
$$

Thus, from Eq. (25) the minimal mesh stiffness can be obtained, $k_{\min } \approx 4.32 \mathrm{e} 8$ $\mathrm{N} / \mathrm{m}$.It can be further found the relation $k_{\max } / k_{\min } \approx 5 / 3 \approx 1.667$. Furthermore, by using these additional stiffness parameters, the time-varying mesh stiffness can also be written in terms of Fourier series [28, 41]. 
Table 1 Parameters utilized to model the spur gear-pinion pair

\begin{tabular}{ccc}
\hline Parameter & Pinion & Gear \\
\hline Number of teeth $\left(Z_{p}, Z_{g}\right)$ & 25 & 31 \\
Pressure angle $(\alpha)$ & \multicolumn{2}{c}{$25^{\circ}$} \\
Modulus & \multicolumn{2}{c}{$3.175 \mathrm{e}-3 \mathrm{~m}$} \\
Center distance & \multicolumn{2}{c}{$3.89 \mathrm{e}-2 \mathrm{~m}$} \\
Tooth face width $(b)$ & $3.175 \mathrm{e}-2 \mathrm{~m}$ \\
Contact ratio $(\varepsilon)$ & \multicolumn{2}{c}{1.433} \\
Moment of inertia $\left(I_{p}, I_{g}\right)$ & $0.0009579 \mathrm{kgm}^{2} \quad 0.00226 \mathrm{kgm}^{2}$ \\
Meshing damping ratio $(\zeta)$ & \multicolumn{2}{c}{0.1} \\
Driving torque $T_{p}$ & \multicolumn{2}{c}{$226 \mathrm{Nm}$} \\
Young's modulus & \multicolumn{2}{c}{$2.069 \mathrm{e} 11 \mathrm{~Pa}$} \\
Poisson's ratio $(v)$ & \multicolumn{2}{c}{0.3} \\
Mass $\left(m_{p}, m_{g}\right)$ & $1.1766 \mathrm{~kg}$ & $1.8209 \mathrm{~kg}$ \\
Load torque $\left(T_{g}\right)$ & \multicolumn{2}{c}{$226 \mathrm{Nm}$} \\
Gear shaft radius & $0.0085 \mathrm{~m}$ & $0.0108 \mathrm{~m}$ \\
Addendum radius & $0.0428 \mathrm{~m}$ & $0.0523 \mathrm{~m}$ \\
Dedendum radius & $0.0357 \mathrm{~m}$ & $0.0452 \mathrm{~m}$ \\
Dimensionless tool tip radius & \multicolumn{2}{c}{0.2} \\
\hline
\end{tabular}

Figure 10 shows the time-varying mesh stiffness of the gear pair evaluated by using the Chaari's approach and Fourier series. In Fig. 10a, $t_{d}$ and $t_{s}$ denote the mesh time for a single-tooth engagement and a double-tooth engagement, respectively. The total mesh cycle time yields $t_{c}=t_{d}+t_{s}$. Fig. $10 \mathrm{~b}$ allows for the comparison between the Chaari's stiffness model and the stiffness model described by Fourier series with different orders. For the convenience of further discussion, let $k_{1}$ be the Chaari's stiffness model, $k_{2}$ and $k_{3}$ be the stiffness model expressed by 5 th and 15 th Fourier series, respectively. By analyzing Fig. $10 \mathrm{~b}$, it can be clearly observed that $k_{3}$ case tends to exhibit a stiffness curve of almost square waves. Based on the gear pair parameters listed in Table 1, the key meshing instant time in a mesh cycle described in Section 3.1 can be evaluated as $t_{c}=1.000 \mathrm{~s}, t_{d}=0.433 \mathrm{~s}, t_{s}=0.567 \mathrm{~s}$ and $t_{p}=0.716 \mathrm{~s}$. 


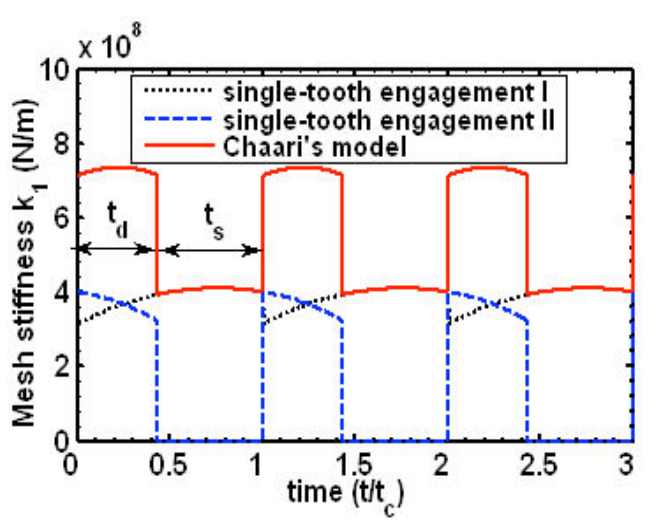

(a) Chaari's time-varying mesh stiffness: $k_{1}$

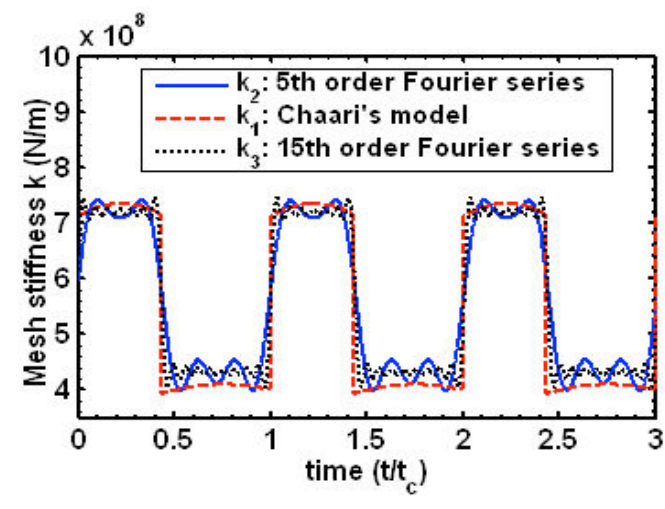

(b) Mesh stiffness described by Fourier series

Fig. 10 Two time-varying mesh stiffness models: Chaari's model and Fourier series model

Figure 11 presents the Dynamic Transmission Error (DTE) outcomes for a low-speed gear system with an initial pinion rotation speed $\omega_{p}=2.4 \mathrm{rpm}$. From Fig. 11 indicates that there are sharp DTE change at instant $t_{d}=0.433 \mathrm{~s}$ for all analyzed cases. For Figs. 11a, 11c, 11d and 11f, which correspond to a time-varying stiffness, this phenomenon can be explained by a sharp mesh stiffness change at the instant when the mesh state transition happens from the single-tooth engagement to the double-tooth engagement (see Fig. 10). While for the results relative to a constant meshing stiffness, $k_{\text {mean }}$, this phenomenon is caused by the sharp changes of the frictional force magnitude, as shown in Figs. 11b and 11e. In addition, from Fig. 11b, a similar sharply impulsive excitation can also be clearly observed at instant $t_{p}=0.716$ $\mathrm{s}$. This effect is caused by a sharp reversal of friction force direction at instant $t=t_{p}$. By analyzing Figs. 11a and 11c, it can be concluded that the frictional force leads to relative larger DTE variations. This phenomenon was recognized in the work by He et al. [49]. Comparing the results shown in Figs. 11c and 11d, it can be found that if the EHD lubrication condition of gear teeth is considered and the frictional coefficient model $\mu_{E H D}$ in Eq. (20) is utilized, the DTE at instant $t_{p}$ shows more stable and smooth results than those based on the frictional coefficient with constant magnitude with Eq. (19) and $\mu_{a v g}=0.1$. Thus, it can be concluded that for the low-speed geared transmission system, the frictional force has an influence on the dynamic responses in a significant manner. 
From Figs. 11a-11d, it can be observed that the DTE exhibits lower values in the double-tooth engagement period than those in the single-tooth engagement period. Furthermore, the DTE results obtained by using Chaari's stiffness model $k_{1}$ are different from those calculated when the Fourier series stiffness models $k_{2}$ and $k_{3}$ are considered, especially at instants $t_{d}$ and $t_{p}$, as shown Figs. 11a, 11c and 11d. Finally, Fig. 11e and 11f depict that the amplitudes of the Static Transmission Error (STE) affect the DTE results in a significant manner. In general, larger STE amplitude induces larger DTE oscillations.

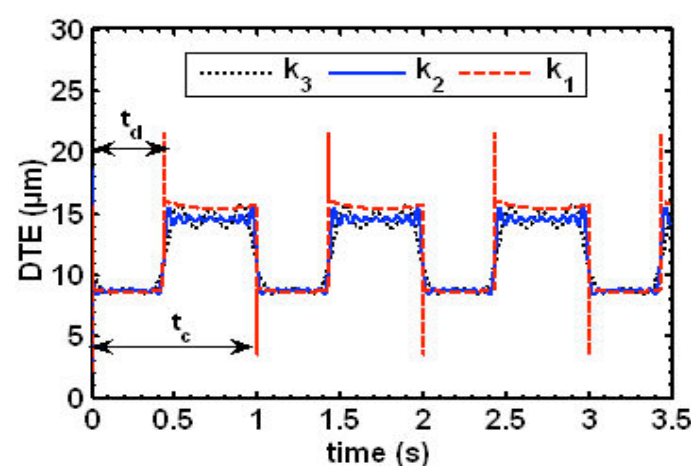

(a) Time-varying stiffness and damping

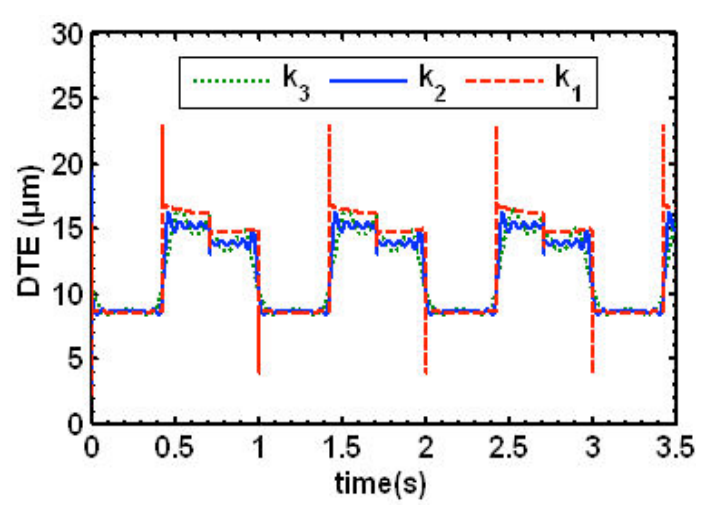

(c) Time-varying stiffness and damping, constant frictional coefficient $\left(\mu_{\text {avg }}=0.1\right)$

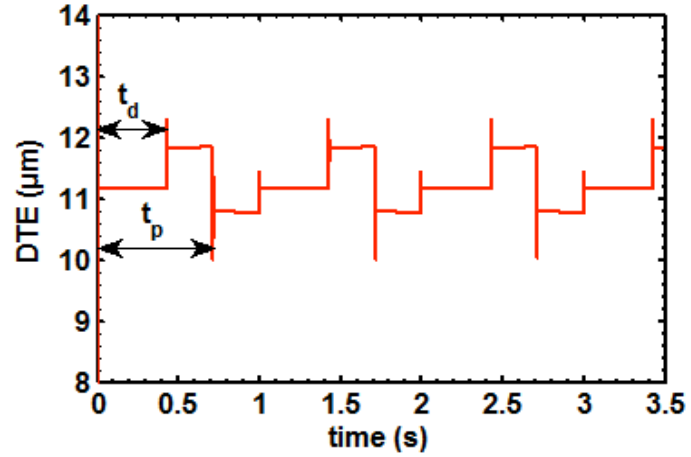

(b) Constant stiffness $\left(k_{\text {mean }}\right)$, damping and frictional coefficient $\left(\mu_{\text {avg }}=0.1\right)$

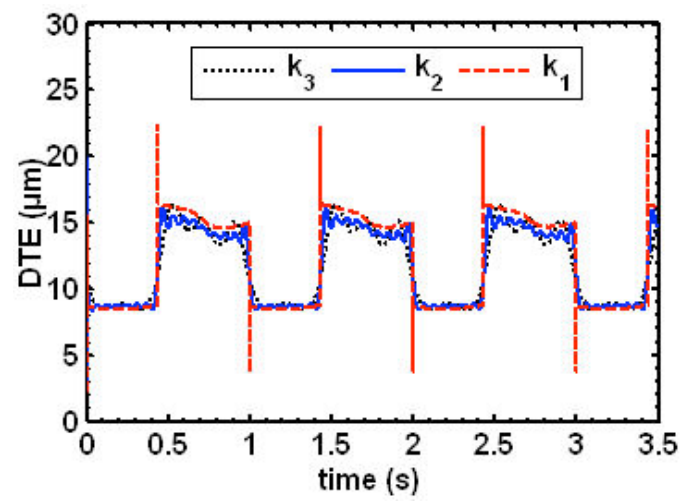

(d) Time-varying stiffness, damping and frictional coefficient $\left(\mu_{E H D}\right)$ 


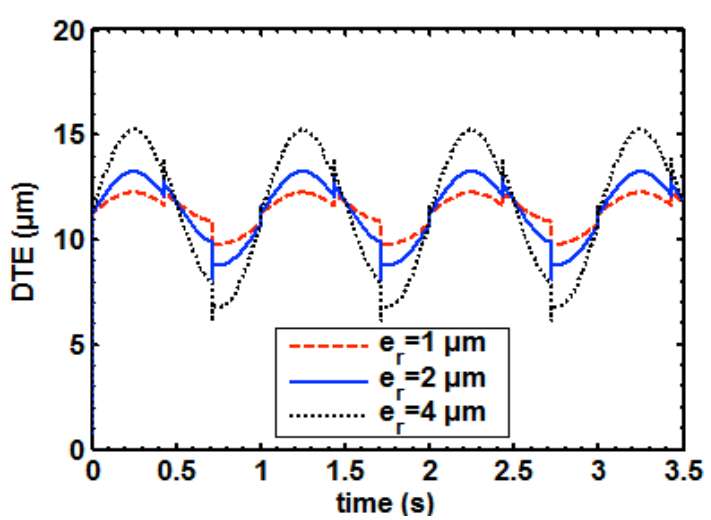

(e) Constant stiffness $\left(k_{\text {mean }}\right)$, damping and frictional coefficient $\left(\mu_{a v g}=0.1\right)$, different STE amplitudes $\left(e_{r}\right)$

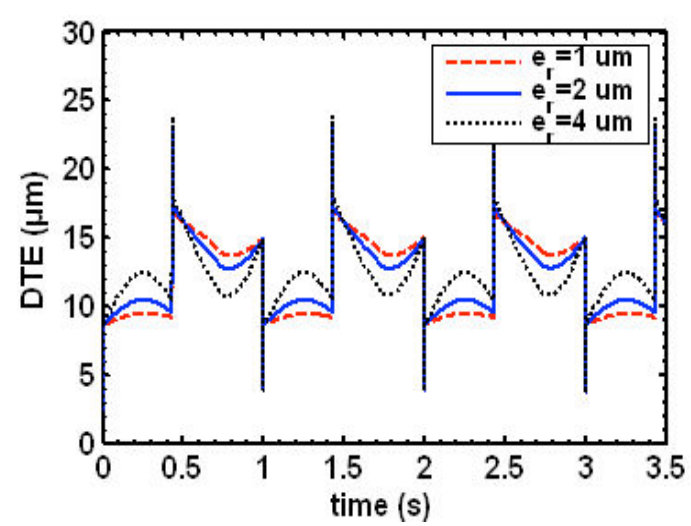

(f) Time-varying stiffness $k_{l}$, damping and frictional coefficient $\left(\mu_{E H D}\right)$, different STE amplitudes $\left(e_{r}\right)$

Fig. 11 Comparison of DTE results for a low-speed gear system with $\omega_{p}=2.4 \mathrm{rpm}$

Figure 12 shows the Dynamic Transmission Error (DTE) outcomes for a high-speed gear system at an initial pinion rotation speed $\omega_{p}=1500 \mathrm{rpm}$. The key meshing instant time within a period is $t_{c}=1.6 \mathrm{~ms}, t_{d}=0.6928 \mathrm{~ms}, t_{s}=0.9072 \mathrm{~ms}$, and $t_{p}=1.146 \mathrm{~ms}$. From Fig. 12, sharp DTE changes at instant $t_{d}=0.6928 \mathrm{~ms}$ in a period for all different cases are clearly visible and can be explained in a similar manner as in the case of low-speed gear system. Comparing the corresponding results for the low-speed gear system, it can be concluded that the influence of the frictional forces on the DTE results is not clear, as it is illustrated in Figs. 12b, 12c and 12d. However, the differences between the results obtained from the time-varying stiffness models and the outcomes from the use of constant mesh stiffness are important. Different from the corresponding results for a low-speed gear system discussed above, the influence of the different time-varying stiffness models on the DTE results of a high-speed gear system is very slight. From Figs. 12e and 12f, it can be observed that the Static Transmission Error (STE) amplitude also affects the DTE results considerably. Some of the results plotted in Fig. 12a, $12 \mathrm{~b}$ and $12 \mathrm{f}$ can also be corroborated by the data in Vaishya and Singh [40] for a similar system. 


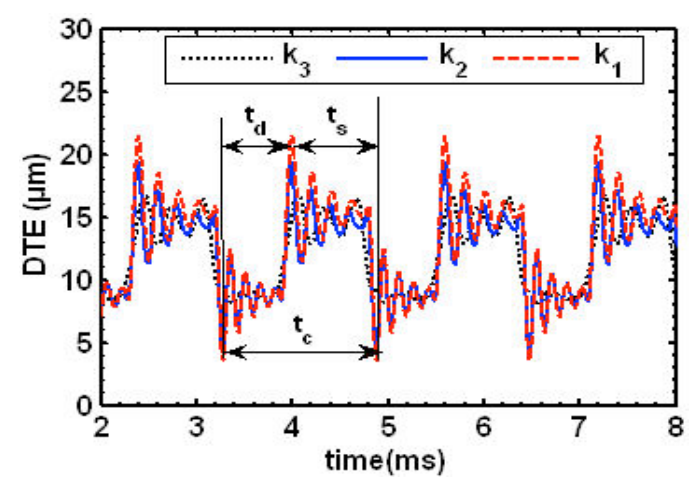

(a) Time-varying stiffness and damping.

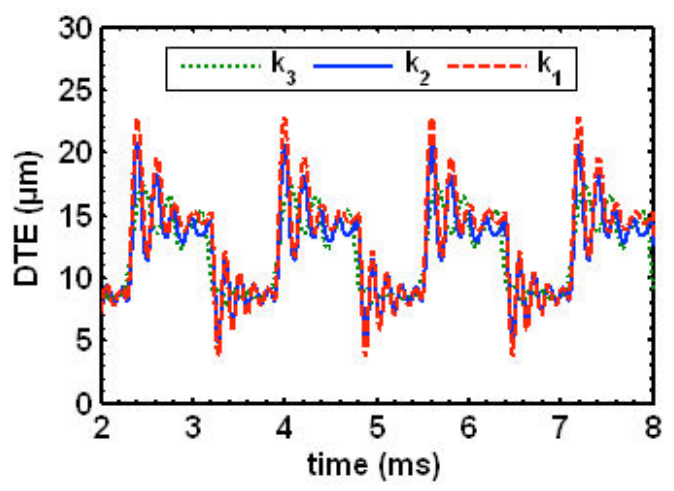

(c) Time-varying stiffness and damping, constant frictional coefficient $\left(\mu_{a v g}=0.1\right)$

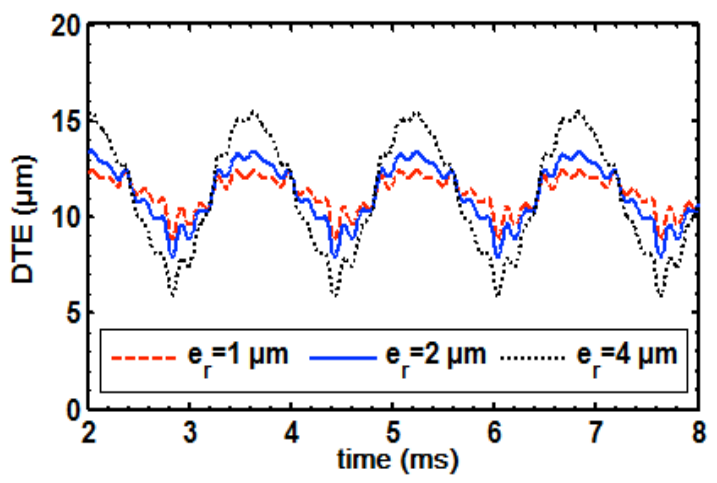

(e) Constant stiffness $\left(k_{\text {mean }}\right)$, damping, frictional coefficient $\left(\mu_{a v g}=0.1\right)$ and different static transmission error amplitudes $\left(e_{r}\right)$

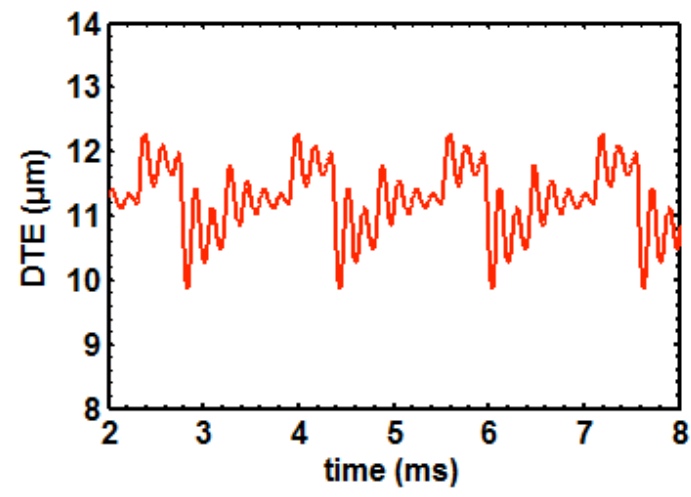

(b) Constant stiffness $\left(k_{\text {mean }}\right)$, damping and frictional coefficient $\left(\mu_{a v g}=0.1\right)$

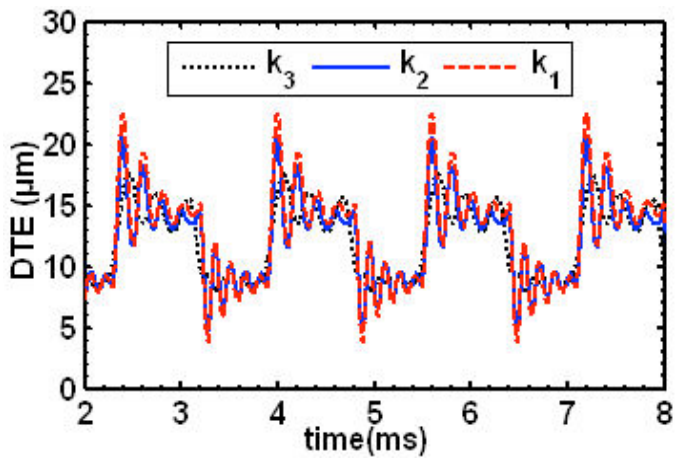

(d) Time-varying stiffness, damping and frictional coefficient $\left(\mu_{E H D}\right)$

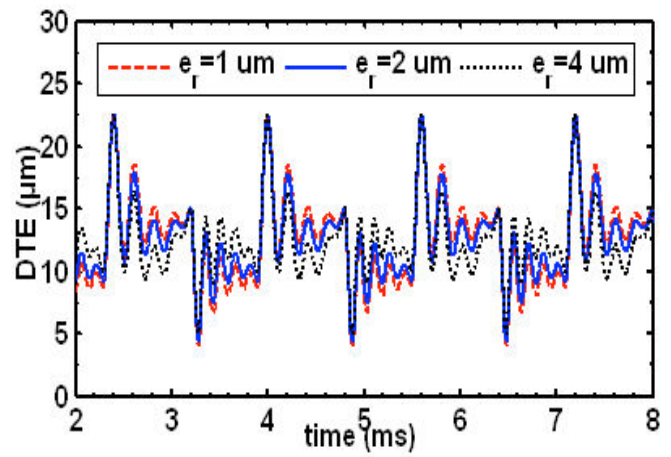

(f) Time-varying stiffness $k_{l}$, damping and frictional coefficient $\left(\mu_{E H D}\right)$, different static transmission error amplitudes $\left(e_{r}\right)$

Fig. 12 Comparison of DTE results for a high-speed gear system with $\omega_{p}=1500 \mathrm{rpm}$

\subsection{Coupling dynamics of a quick-return mechanism driven by a geared rotor}

In this section, the coupling dynamics of a quick-return mechanism driven by a geared rotor with two flexible shafts is investigated. The gear centers coincide with the mid points of the two parallel flexible shafts shown in Fig. 13. The two flexible shafts are supported by 4 bearings of the same kind, which are labeled as I-IV and 
modeled as 4 lubricated cylindrical joints. The pinion and the gear have the same geometrical and material properties. Table 2 presents the system parameters. This example has been studied by Chang [37], in which, however, the gear mesh friction forces and the lubrication conditions were taken into account. In the present study, the influences of the gear mesh stiffness models, friction models, amplitude of STE and EHD lubrication conditions on the system dynamic responses are analyzed. In a similar way to Chang [37], the system with the geared rotor is called the coupled system, while the system without the geared rotor (only a perfect quick-return mechanism) is named as the uncoupled system. In the coupled system when the lubrication conditions of the corresponding 4 cylindrical joints are not considered, the 4 bearings supporting the flexible shafts are modeled as spring-damper elements. The spring stiffness coefficient $\left(k_{b}\right)$ and damping coefficient $\left(c_{b}\right)$ in each direction are assumed to be $10^{6} \mathrm{~N} / \mathrm{m}$ and $3000 \mathrm{Ns} / \mathrm{m}$, respectively. The whole system is modeled by using the ACB method, as described in Section 2. The origin of the global coordinate system is located at the point $O$, which coincides with the mass center of the pinion $\left(-90^{\circ}\right)$. The rigid crank is initially aligned with the positive direction of $Z$-axis. From Fig. 13, it can be observed that there is a sliding joint connecting the rigid crank and the flexible rod. For the purpose of modeling the sliding joint based on ANCF, the approach proposed by Seo et al. [69] is adopted.

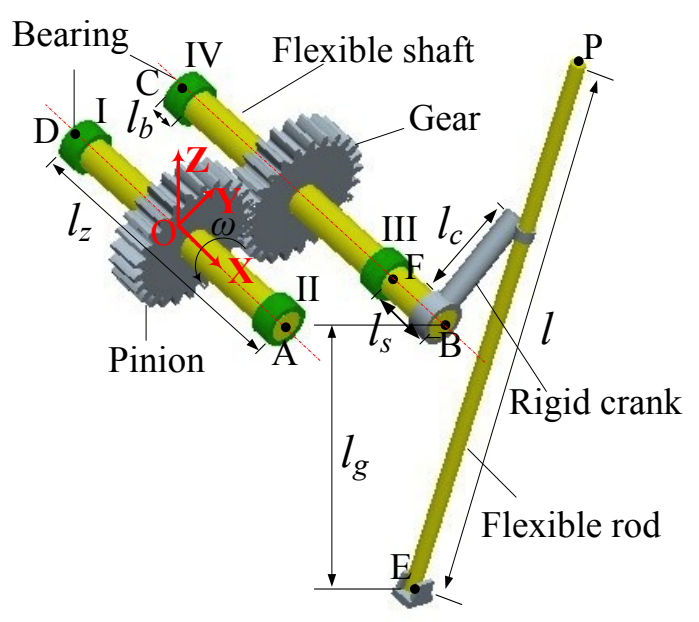

Fig. 13 Quick-return mechanism driven by a geared rotor supported by 4 cylindrical joints 
Table 2 Simulation parameters of the quick-return mechanism

\begin{tabular}{|c|c|}
\hline Parameter & Value \\
\hline Number of gear teeth & $Z_{p}=Z_{g}=28$ \\
\hline Pressure angle of gear pair & $\alpha=20^{\circ}$ \\
\hline Modulus & $3.383 \mathrm{e}-3 \mathrm{~m}$ \\
\hline Radius of base circle & $r_{b p}=r_{b g}=44.5 \mathrm{~mm}$ \\
\hline Gear moment of inertia & $I_{p}=I_{g}=0.0018 \mathrm{kgm}^{2}$ \\
\hline Gear and pinion mass & $1.84 \mathrm{~kg}$ \\
\hline Young's modulus of gear and pinion material & $20.7 \mathrm{GPa}$ \\
\hline Addendum radius & $50.7 \mathrm{~mm}$ \\
\hline Dedendum radius & $43.1 \mathrm{~mm}$ \\
\hline Dimensionless tool tip radius & 0.2 \\
\hline Meshing damping ratio & $\zeta=0.1$ \\
\hline Rotating speed & $100 \mathrm{rad} / \mathrm{s}$ \\
\hline Cross-radius of flexible shafts & $37 \mathrm{~mm}$ \\
\hline Young's modulus of shaft material & $70 \mathrm{GPa}$ \\
\hline Flexible shaft length & $l_{z}=268 \mathrm{~mm}$ \\
\hline Cross-radius of flexible rod & $d=50 \mathrm{~mm}$ \\
\hline Material density of flexible rod & $\rho=3641.5 \mathrm{~kg} / \mathrm{m}^{3}$ \\
\hline Cylindrical joint bearing width & $l_{b}=14 \mathrm{~mm}$ \\
\hline Cylindrical joint bearing thickness & $10 \mathrm{~mm}$ \\
\hline Rigid crank length & $l_{c}=0.0059997 \mathrm{~m}$ \\
\hline Length of flexible rod & $l=1 \mathrm{~m}$ \\
\hline Distance between bearing III end surface to point B & $l_{s}=23 \mathrm{~mm}$ \\
\hline Vertical distance between points $\mathrm{B}$ and $\mathrm{E}$ & $l_{g}=0.59997 \mathrm{~m}$ \\
\hline Poisson's ratio of all materials & 0.3 \\
\hline Density of other parts & $\rho=7800 \mathrm{~kg} / \mathrm{m}^{3}$ \\
\hline Lubricant dynamic viscosity & $\tau=0.04 \mathrm{Pas}$ \\
\hline
\end{tabular}

Figure 14 presents the deflection results of flexible rod tip for the systems with 4 un-lubricated cylindrical joints and different gear pair contact models. For the results in Figs. $14 \mathrm{~b}$ and $14 \mathrm{e}$, the constant mesh stiffness is set as $k=1.0 \mathrm{e} 8 \mathrm{~N} / \mathrm{m}$. For the results in Fig. 14c, the mesh stiffness model of the Fourier series, the maximal and minimal values of the mesh stiffness coefficient are set as $k_{\max }=1.20 \mathrm{e} 8 \mathrm{~N} / \mathrm{m}$ and $k_{\min }=0.72 \mathrm{e} 8$ N/m. By analyzing Fig. 14a, it can be observed that the rod tip deflections are much smaller for the uncouple system than those for the coupled system, as shown in Figs. 14b-14f. Thus, it can be concluded that the geared rotor plays an important role in the tip deflection. Moreover, from the results shown in Figs. 14b-14d, it can be observed 
that the influence of the gear mesh stiffness model and the sliding friction force model of gear mesh on the rod tip deflections is not significant. From the analysis of the results in Figs. 14e and 14f, the Static Transmission Error (STE) amplitude $\left(e_{r}\right)$ affects the rod tip deflection in a significant manner. The rod tip deflection increases with an increase of the STE amplitude. By analyzing Figs.14e and 14f, it can be concluded that the rod tip deflections are slightly larger for the systems with the forces of sliding friction than those for the corresponding systems without the forces of sliding friction. It can be said in general that the outcomes reported here are corroborated by the published literature [37].

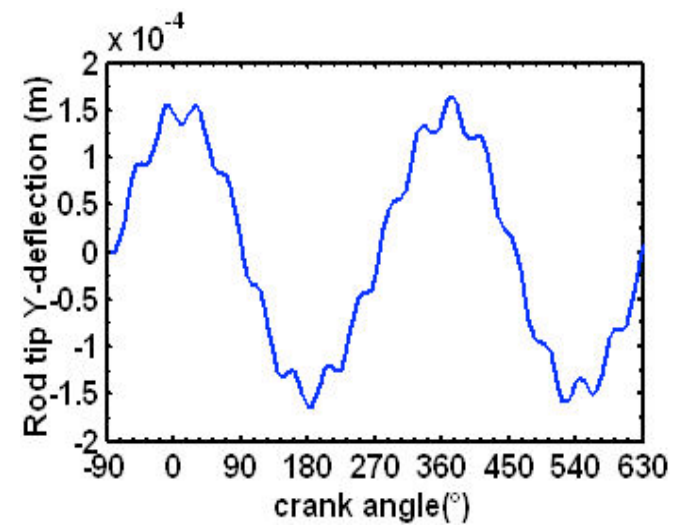

(a) Uncoupled system

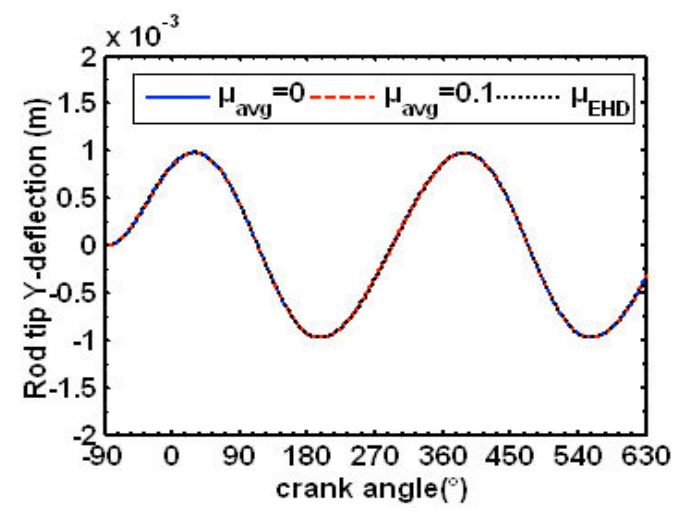

(c) Coupled systems: Fourier series mesh stiffness model and different frictional coefficient models

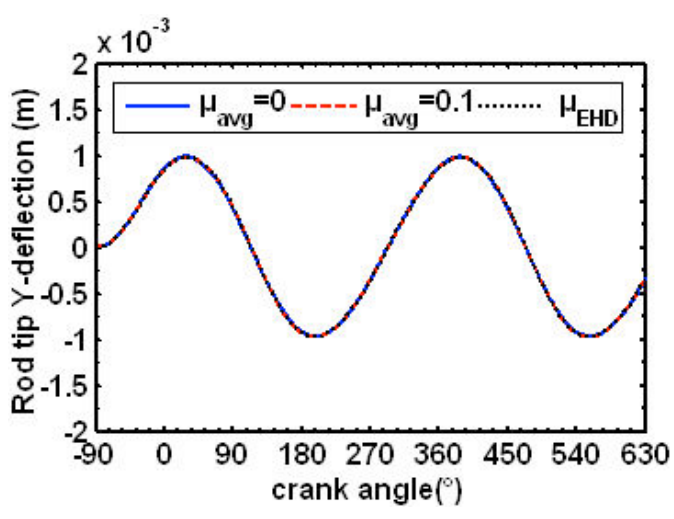

(b) Coupled systems: constant mesh stiffness and different frictional coefficient models

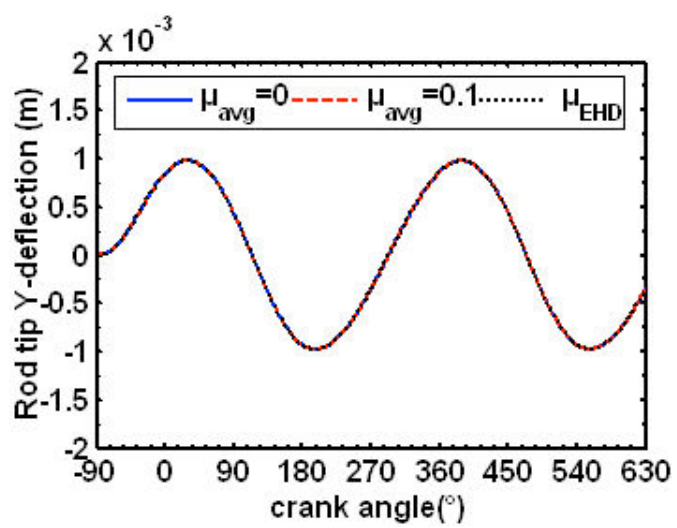

(d) Coupled systems: Chaari's mesh stiffness model and different frictional coefficient models 


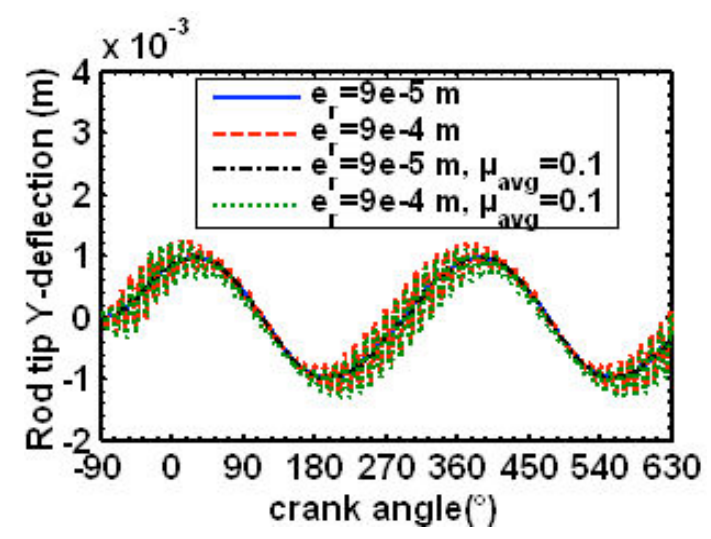

(e) Coupled systems: constant mesh stiffness model and constant frictional coefficient models, different static transmission error amplitudes $\left(e_{r}\right)$

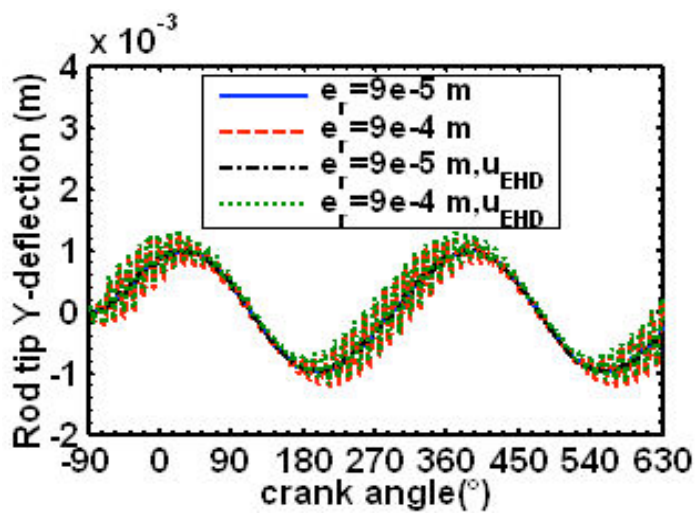

(f) Coupled systems: Chaari's mesh stiffness model, time-varying frictional coefficient $\left(\mu_{E H D}\right)$ and different static transmission error amplitudes $\left(e_{r}\right)$

Fig. 14 Influence of the gear mesh models on the rod tip deflection (un-lubricated cylindrical joints)

Figure 15 shows the influence of the gear pair contact models on the rod tip motion in $Y$-direction, where $k$ represents the constant mesh stiffness model, $k_{1}$ and $k_{2}$ denote the mesh stiffness model described by using Fourier series and Chaari's stiffness model, respectively. Again, for this example, the difference of the mesh stiffness models lead to slight difference of the tip rod motions only. In contracts, Fig. $15 \mathrm{~d}$ shows a significant influence of the STE amplitudes and frictional forces on the rod tip velocity.

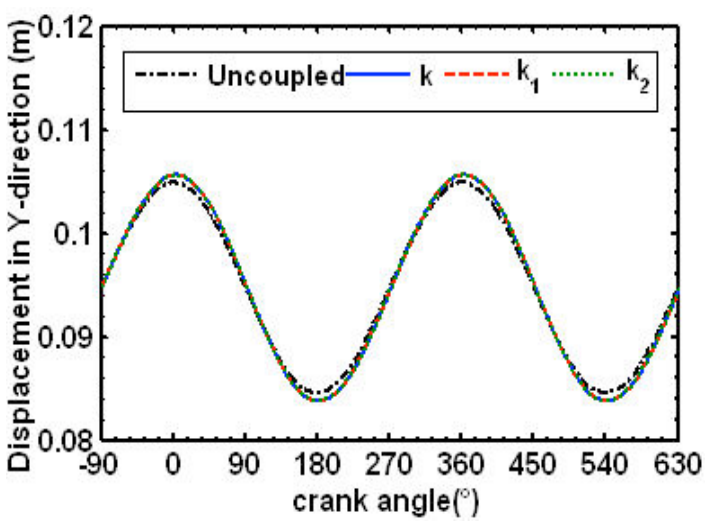

(a) Displacement results

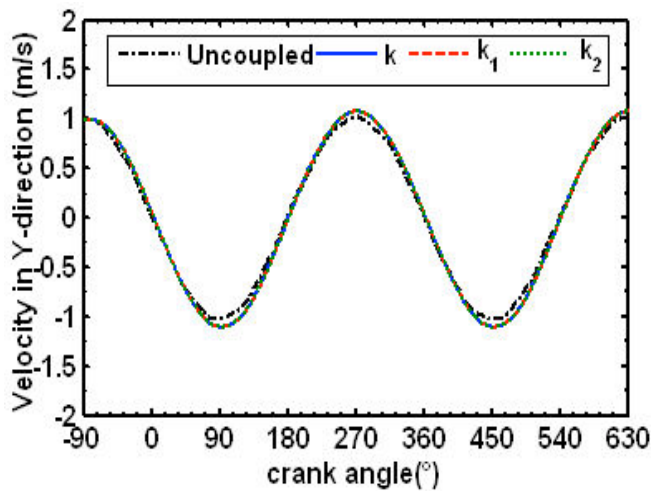

(b) Velocity results 


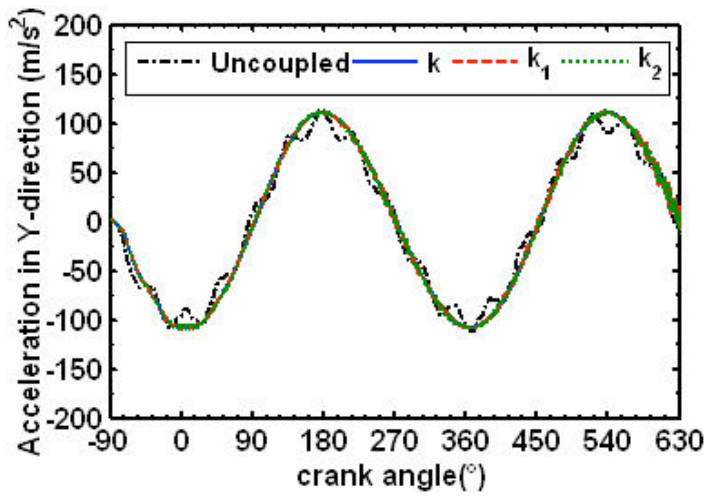

(c) Acceleration results

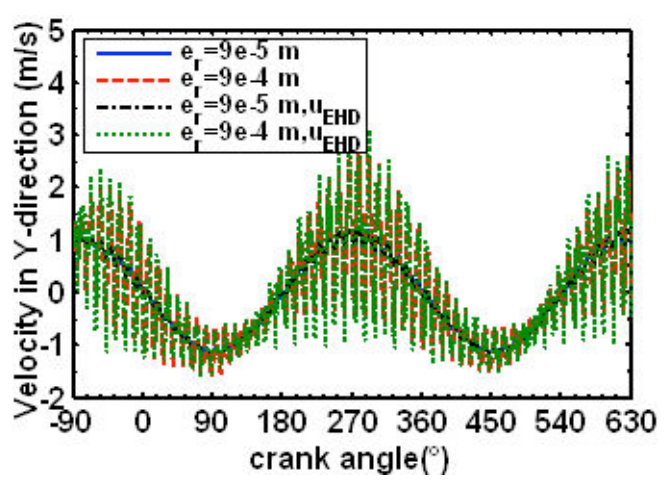

(d) Influence of the STE amplitudes and frictional forces on rod tip velocity

(Chaari's mesh stiffness model)

Fig. 15 The influence of the gear mesh models on the rod tip motion (un-lubricated cylindrical joints)

Figure 16 presents the influence of the joint clearance size $c$ and STE amplitude $e_{r}$ on the rod tip deflection for the system with $4 \mathrm{HD}$ lubricated cylindrical joints. For HD lubricated cylindrical joints, the bearings are assumed to be rigid and the coupling behaviors between the lubricant pressure $p$ and the bearing deformation $\delta$ in Eq. (22) is not taken into consideration. From the analysis of Fig. 16a, it can be obseved that larger clearance size leads to the larger rod tip deflection. Comparing the results shown in Fig. 16a with those for the coupled system in Fig. 14, it can be found that the rod tip deflections for the HD lubricated systems are smaller than those for the coupled systems, in which the cylindirical jont bearings are just simpliy modeled as the spring-damper systems. It should be pointed out that is is not easy to determine the spring stiffness coefficient $\left(k_{b}\right)$ and the damping coefficient $\left(c_{b}\right)$ for the spring-damper model in practice. Thus, the introduction of the practical lubricant parameters and the HD or EHD lubrication conditions in the modeling process can lead to more accurate outcomes. From Fig. 16b, the influence of the STE amplitude on the rod tip deflection is clear. In addition, by comparing the results shown in Fig. 16b with those in Fig. 14e and 14f, it can be asserted that the rod tip deflections for the HD lubricated case are smaller than those for the coupled un-lubricated systems. It is also found that the larger amplitude of STE lead to more difficult simulation convergence because of the coupling effect between the large meshing forces and the lubrication forces. 


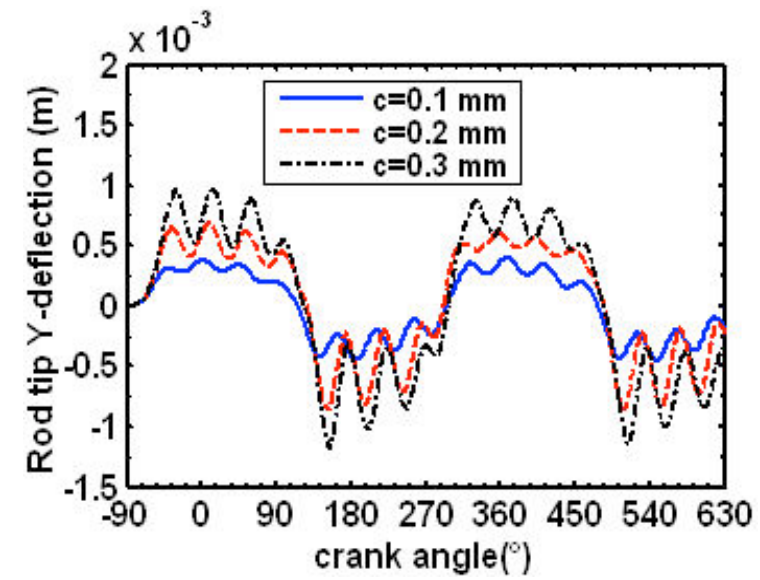

(a) Effect of clearance size

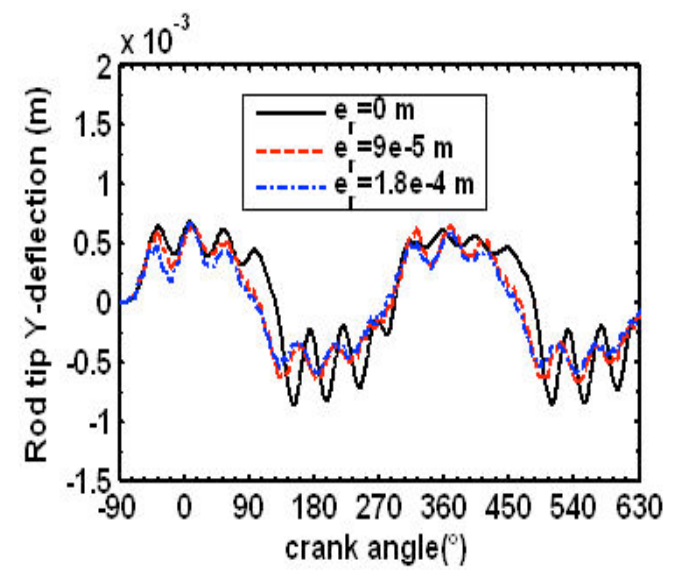

(b) Effect of amplitude of STE $(c=0.2 \mathrm{~mm})$

Fig. 16 Influence of the joint clearance size and STE amplitude on the rod tip deflection (HD lubricated cylindrical joints)

In what follows, the influence of the EHD conditions on the dynamic responses of the geared mechanism is investigated. The approach to define the EHD lubricated cylindrical joints has been described in Section 2. The nodes of the outer surfaces of the 4 flexible bearings are fixed in the ground. Figure 17 shows influence of the joint clearance size $c$ and lubrication conditions on the rod tip deflection, from which it can be observed that a larger clearance size leads to a larger rod tip deflection. The influence of the STE amplitude on the rod tip deflection for the EHD lubricated case is also significant, and the rod tip deflection curves are close to those in Fig.16b.

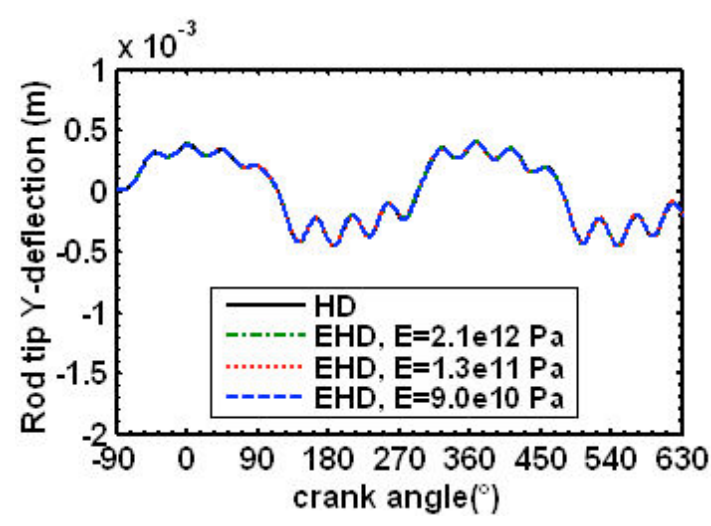

(a) $c=0.1 \mathrm{~mm}$

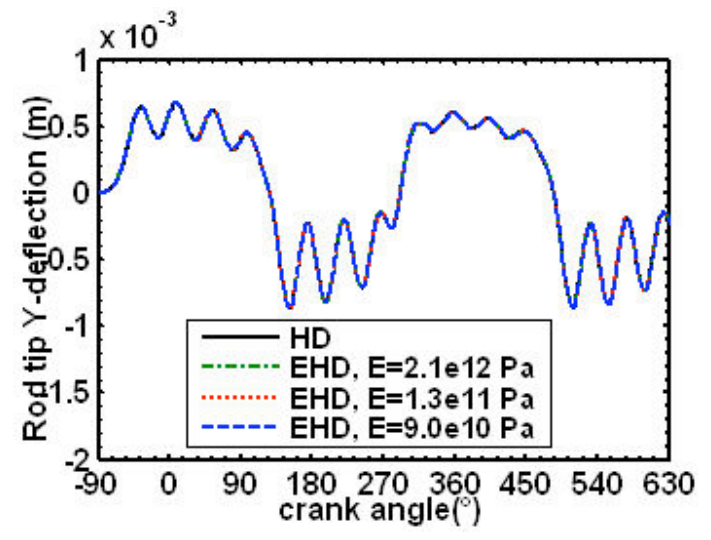

(b) $c=0.2 \mathrm{~mm}$ 


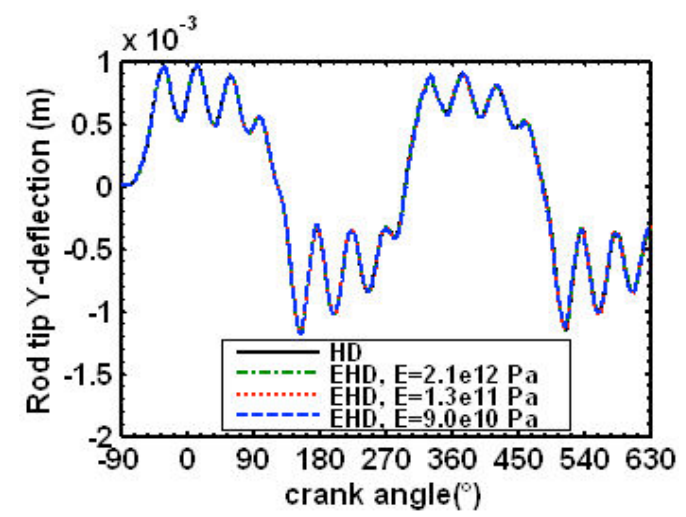

(c) $c=0.3 \mathrm{~mm}$

Fig. 17 Influence of the joint clearance size $c$ and lubrication conditions on the rod tip deflection

Figure 18 shows influence of the lubrication conditions (HD and EHD) and the STE amplitudes on the rod tip kinematics. It can be observed that the velocity and acceleration results for HD or EHD lubricated systems exhibit larger oscillations than the results for uncoupled system. Moreover, by a careful analysis to Fig.18c, it can be concluded that the acceleration results for the EHD lubricated system changes more sharply than those for the HD lubricated systems. This phenomenon is caused by the bearing deformations. Moreover, the larger STE amplitudes will cause significant changes in the velocity outcomes, as shown in Fig.18d.

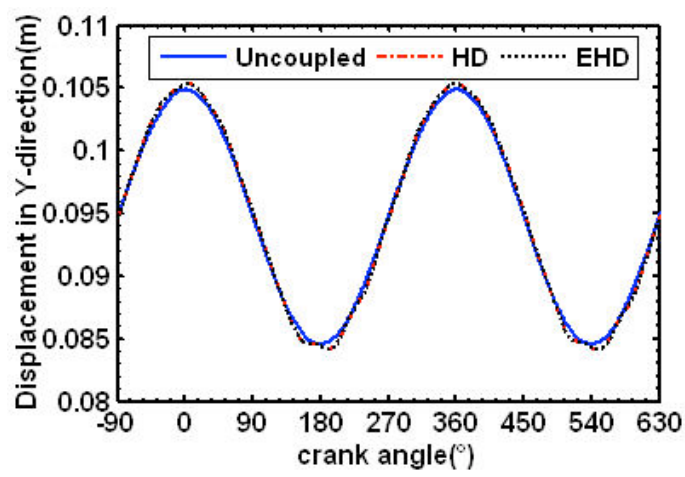

(a) Displacement results

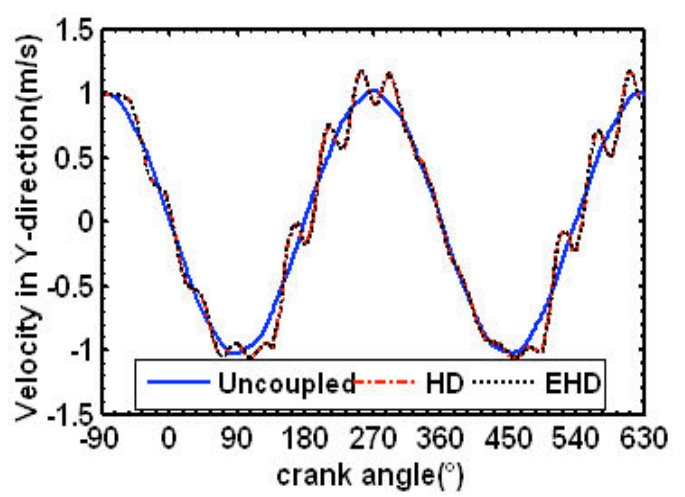

(b) Velocity results 


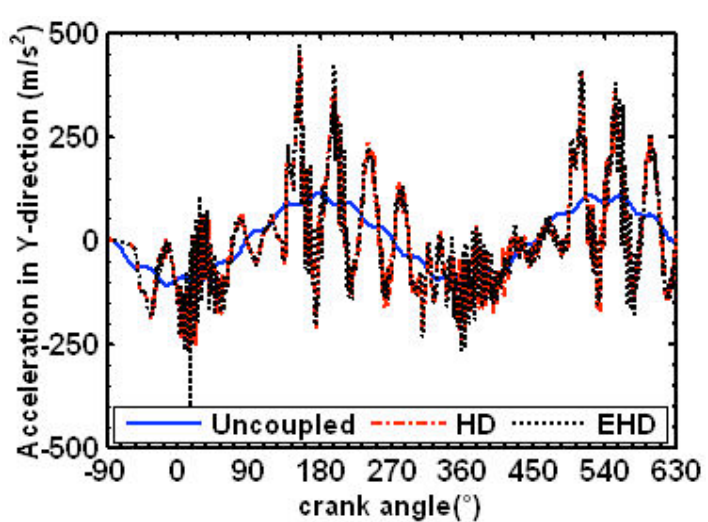

(c) Acceleration results

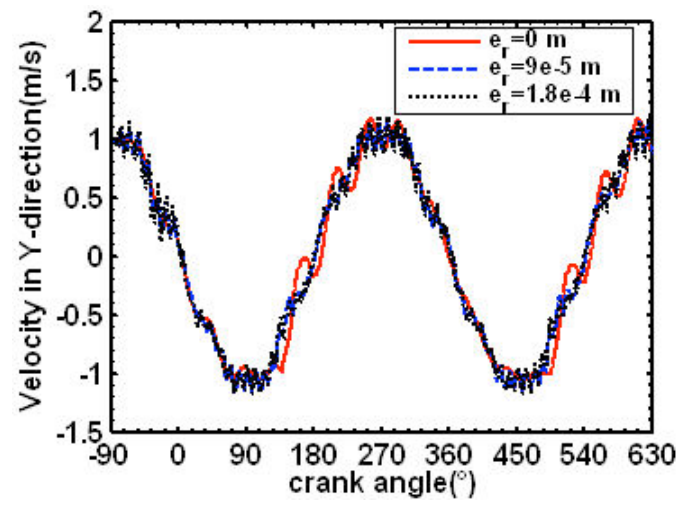

(d) Influence of the STE amplitudes on rod tip velocity (EHD)

Fig. 18 Influence of the lubrication conditions (HD and EHD) on the rod tip movements $(c=0.2 \mathrm{~mm}, E=1.3 \mathrm{e} 11 \mathrm{~Pa})$

Figure 19 presents the trajectories of surface centers $A, D, C$ and $F$ of shaft end in the clearance sapce. With intent to visualize the results more clearly and with the intent to keep the figures clear and readable, only the data relative to the period when the crank angle change from $-90^{\circ}$ to $270^{\circ}$ are showed here. It can be observed that the directions of the trajectories of surface centers $A$ and $D$ are near to the direction of gear Line-Of-Action (LOA). The reason for this phenomenon is that the directions of the trajectories of the centers $A$ and $D$ are mainly determined by the gear mesh force along the direction of gear LOA. The trajectories of shaft end surface centers $C$ and $F$ are much different from those of the centers $A$ and $D$, becasue the trajectories of the centers $C$ and $F$ will not only be affected by the mesh force but also by the dynamic behaviors of the rigid crank and flexible rod. As the center $F$ are closer to the the rigid crank and flexible rod, the direction of its trajectory is farer away from the direction of LOA than the direction of center $C$. 

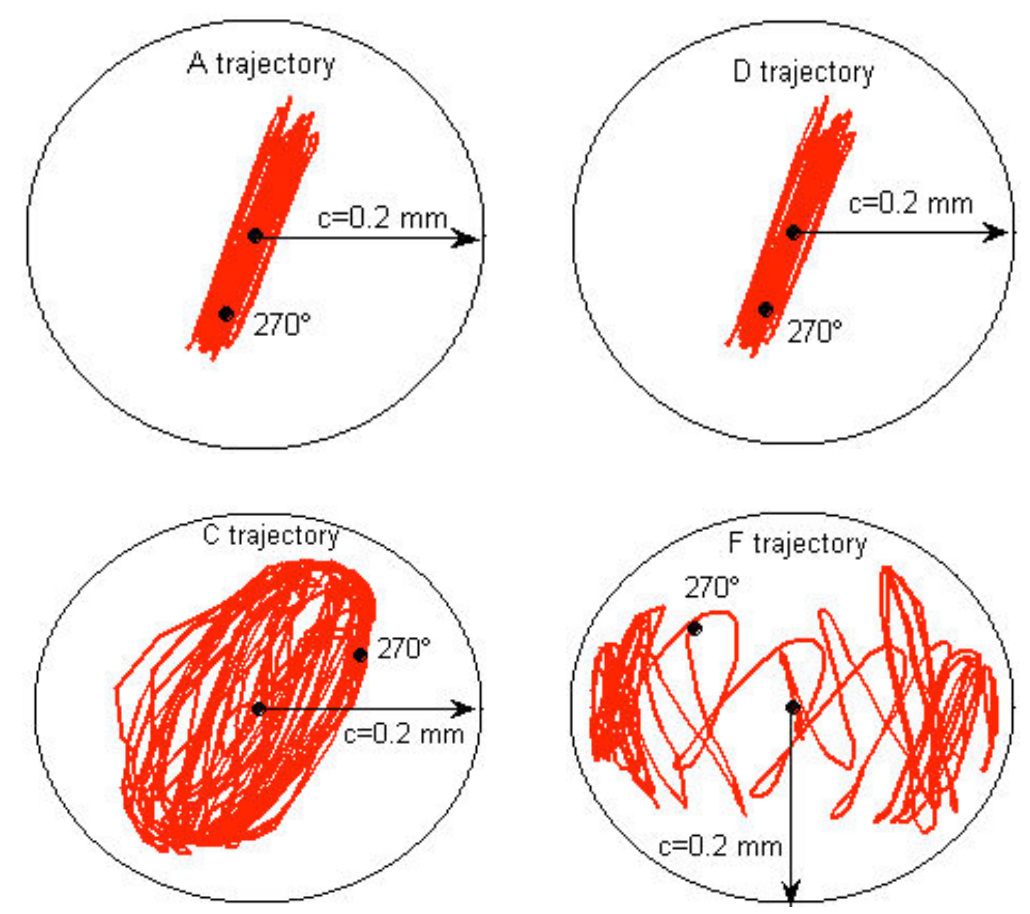

Fig. 19. Trajectories of surface centers $A, D, C$ and $F$ of the shaft end in the clearance space $\left(E=1.3 \mathrm{e} 11 \mathrm{~Pa}, c=0.2 \mathrm{~mm}, e_{\mathrm{r}}=1.8 \mathrm{e}-4 \mathrm{~m}\right.$, crank angle from- $90^{\circ}$ to $270^{\circ}$ )

Finally, Fig. 20 shows the lubricant pressure contours and distributions around the journal and the flexible bearing, von Mises stress contours of a EHD lubricated system when its crank angle is equal to be $90^{\circ}$. From Fig. 20a, it can be observed that the directions of the lubrication pressure for the cylindrical joints I and II are close to the direction of gear pair LOA, which is in line with the directions of the centers $A$ and $D$ (shown in Fig. 19). By comparing Fig. 20a with Fig. 20b, the magnititude of the lubricant pressure and its distribution are consistent with the magnititude of the von Mises stress and its distribution of the flexible bearing, respectively. 


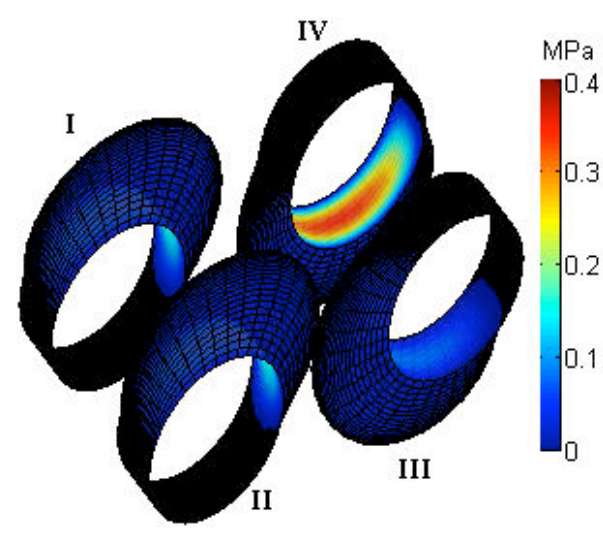

(a) Lubricant pressure distribution and contour

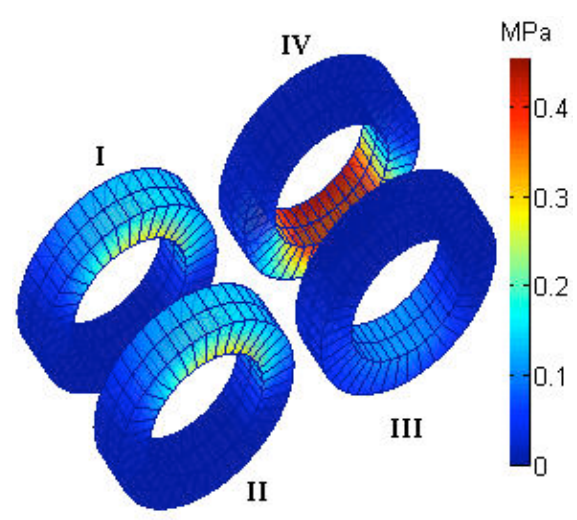

(b) von Mises stress contour of flexible bearing

Fig. 20. Scaled view of lubricant pressure contours and spatial distributions of von Mises stress contours of 4 flexible bearings $\left(E=1.3 \mathrm{e} 11 \mathrm{~Pa}, c=0.2 \mathrm{~mm}, e_{\mathrm{r}}=1.8 \mathrm{e}-4 \mathrm{~m}\right.$, crank angle $\left.=90^{\circ}\right)$

\section{Conclusions}

The coupling dynamics of geared multibody system supported by Elastohydrodynamic (EHD) lubricated cylindrical joints is investigated throughout this work. The dynamic model is established by using the Absolute-Coordinate-Based (ACB) method that combines the Natural Coordinate Formulation (NCF) describing rigid bodies (gears) and the Absolute Nodal Coordinate Formulation (ANCF) describing flexible bodies (rotating shafts, flexible bearing). Firstly, the difference of a constant mesh stiffness model and two time-varying mesh stiffness models (the Chaari's model and the model described by the Fourier series) are noticed via a comparatively study of a classic geared pair at low or high rotating speed. In addition, the influence of the forces of teeth sliding friction on the dynamic responses are investigated by using the Coulomb's friction models with a constant and a time-varying coefficient of friction under EHD lubrication condition of gear teeth. It is found that when the EHD lubrication condition is introduced to the gear teeth, the system exhibits more stable and smooth responses. Finally, the coupling dynamics of a quick-return mechanism driven by a geared rotor with two flexible shafts supported by 4 EHD lubricated cylindrical joints is studied. The influence of the lubrication conditions (HD and EHD), the gear mesh force models and the clearance size on the system responses are also analyzed. Several coupling dynamic behaviors of the 
system are observed, such as the coupling between the trajectories of shaft end surface centers, the gear mesh forces, the lubricant pressure and the von Mises stress of flexible bearing. The methodology proposed in this work can be extended to studying the coupling dynamics of many other geared multibody systems, such as the large hoop truss satellite antenna jointed by using bevel gears.

\section{Acknowledgments}

This work is supported in part by National Natural Science Foundations of China under Grant 11290151, 11221202 and 11002022. The work is also supported in part by the Beijing Higher Education Young Elite Teacher Project under Grant YETP1201.

\section{References}

1. Muvengei, O., Kihiu, J., Ikua, B.: Numerical study of parametric effects on the dynamic response of planar multi-body systems with differently located frictionless revolute clearance joints. Mech. Mach. Theory, 53, 30-49 (2012)

2. Flores, P., Ambrósio, J., Claro, J.C.P., Lankarani, H.M.: Dynamic behaviour of planar rigid multibody systems including revolute joints with clearance. Proc. Inst. Mech. Eng, Part K: J. Multibody Dynamics, 221(2), 161-174 (2007)

3. Tian, Q., Zhang, Y., Chen L., Flores, P.: Dynamics of spatial flexible multibody systems with clearance and lubricated spherical joints. Comput. Struct. 87, 913-929 (2009)

4. Erkaya, S., Uzmay, İ.: Experimental investigation of joint clearance effects on the dynamics of a slider cranker mechanism. Multibody Syst. Dyn. 20, 69-83 (2010)

5. Flores, P.: Modeling and simulation of wear in revolute clearance joints in multibody systems. Mech. and Mach. Theory, 44(6), 1211-1222 (2009)

6. Flores, P., Lankarani, H.M., Ambrósio, J., Claro, J.C.P.: Modelling lubricated revolute joints in multibody mechanical systems. Proc. Inst. Mech. Eng, Part K: J. Multibody Dynamics, 218(4) 183-190 (2004)

7. Tian, Q., Liu, C., Machado, M., Flores, P.: A new model for dry and lubricated cylindrical joints with clearance in spatial flexible multibody systems. Nonlinear Dyn. 64, 25-67 (2011)

8. Flores, P., Lankarani, H.M.: Spatial rigid-multi-body systems with lubricated spherical clearance joints: modeling and simulation. Nonlinear Dyn, 60, 99-114 (2010)

9. Stefanelli, R., Valentini, P.P., Vita. L.: Modeling of hydrodynamic journal bearing in spatial multibody systems. In: ASME International Design Engineering Technical Conference, California, USA, DETC2005-84858 (2005)

10. Brutti, C., Coglitore, G., Valentini, P.P.: Modeling 3D revolute joint with clearance and contact stiffness. Nonlinear Dyn. 66, 531-548 (2011)

11. Liu C, Tian Q, Haiyan Hu.: Dynamics and control of a spatial rigid-flexible multibody system with multiple cylindrical clearance joints. Mech. Mach. Theory. 52, 106-129 (2012) 
12. Pinkus, O., Sternlicht, S.A.: Theory of Hydrodynamic Lubrication McGraw Hill, New York (1961)

13. Tian, Q., Zhang, Y., Chen, L., Yang, J.: Simulation of planar flexible multibody systems with clearance and lubricated revolute joints. Nonlinear Dyn. 60(4), 489-511 (2010)

14. Dowson, D., Ehret, P.: Past, present and future studies in elastohydrodynamics. Proc. Inst. Mech. Eng. J. 213(5), 317-333 (1999)

15. Lugt, P.M., Morles-Espejel, G.E.: A review of Elasto-Hydrodynamic lubrication theory. Tribol. T. 54, 470-496 (2011)

16. Liu, H.P., Xu, H., Ellision, P.J., Jin, Z.M.: Application of computational fluid dynamics and Fluid-Structure Interaction method to the lubrication study of a rotor bearing System. Tribol. Lett. 38(3), 325-336 (2010)

17. Shenoy, B.S, Pai, R.S, Rao, D.S. Pai, R.: Elasto-hydrodynamic lubrication analysis of full $360^{\circ}$ journal bearing using CFD and FSI techniques. World journal of modeling and simulation. 2009 (4), 315-320.

18. Attia, H.M., Bouziz, S., Maatar, M., Fakhfakh, T., Haddar, M.: Hydrodynamic and elastohydrodynamic studies of a cylindrical journal bearing. J. Hydrodyn. 22(2), 155-163 (2010)

19. Slim, B., Tahar, F., Mohamed, H.: Acoustic analysis of hydrodynamic and elasto-hydrodynamic oil lubricated journal bearings. J. Hydrodyn. 24(2), 250-256 (2012)

20. Tian Q, Sun Y L, Liu C, Haiyan Hu, P. Flores. Elastohydrodynamic lubricated cylindrical joints for rigid-flexible multibody dynamics. Comput. Struct. 114-115, 106-120 (2013)

21. García De Jalón, J., Bayo, E.: Kinematic and Dynamic Simulation of Multibody Systems the Real-Time Challenge. Springer, New York (1994)

22. Shabana, A.A.: An absolute nodal coordinates formulation for the large rotation and deformation analysis of flexible bodies. Technical Report. No. MBS96-1-UIC, University of Illinois at Chicago (1996)

23. Schiehlen, W.: Research trends in multibody system dynamics. Multibody Syst. Dyn. 18, 3-13 (2007)

24. Shabana A.A.: Flexible multibody dynamics review of past and recent developments. Multibody Syst. Dyn. 1, 189-222 (1997)

25. Özgüven, H.N., Houser, D.R.: Mathematical models used in gear dynamics a review. J. Sound Vib. 121(3), 383-411 (1988)

26. Kahraman, A., Singh, R.: Nonlinear dynamics of a geared rotor bearing system with multiple clearances. J. Sound Vib. 144(3), 469-506 (1991)

27. Kahraman, A., Singh, R.: Interactions between time-varying mesh stiffness and clearance nonlinearities in a geared system. J. Sound Vib. 146(1), 135-156 (1991)

28. Theodossiades, S., Natsiavas, S.: On geared rotordynamic systems with oil journal bearings. J. Sound Vib. 243(4), 721-745 (2001)

29. Shiau, T.N., Chou, Y.W., Chang, J.R., Nelson, H.D.: A study on the dynamic characteristics of geared rotor-bearing system with hybrid method, International Gas Turbine and Aeroengine Congress and Exposition, The Hague, Netherlands (1994).

30. Fernandez del Rincon, A., Viadero, F., Iglesias, M., García, P., de-Juan, A., Sancibrian, R.: A model for the study of meshing stiffness in spur gear transmissions. Mech. Mach. Theory, 61, 
30-58 (2013)

31. Rao, J.S., Shiau, T.N., Chang, J.R.: Theoretical analysis of lateral response due to torsional excitation of geared rotors. Mech. Mach. Theory 33, 761-783 (1998)

32. Machado, M., Moreira, P., Flores, P., Lankarani, H.M.: Compliant contact force models in multibody dynamics: evolution of the Hertz contact theory. Mech. Mach. Theory, 53, 99-121 (2012)

33. Baguet, S., Jacquenot, G.: Nonlinear coupling in a gear-shaft-bearing system. Mech. Mach. Theory 45, 1777-1796 (2010)

34. Wan, C., Jian, C.: Nonlinear analysis for gear pair system supported by long journal bearings under nonlinear suspension. Mech. Mach. Theory 45, 569-583 (2010)

35. Vinayak, H., Singh, R.: Multibody dynamics and model analysis of compliant gear bodies. J. Sound Vib. 210, 171-214 (1998)

36. Wang, Y., Cheung, H.M.E., Zhang, W.J.: Finite element modelling of geared multibody system. Communications in Numerical Methods in Engineering. 18, 765-778 (2002)

37. Chang, J.R.: Coupling effect of flexible geared rotor on quick-return mechanism undergoing three-dimensional vibration. J. Sound Vib. 300, 139-159 (2007)

38. Martin, K.F.: A review of friction predictions in gear teeth. Wear 49, $201-238$ (1978)

39. Vaishya, M., Singh, R.: Strategies for modeling friction in gear dynamics. J. Mech. Des. 125, 383-393 (2003)

40. Vaishya, M., Singh, R.: Analysis of periodically varying gear mesh systems with coulomb friction using floquet theory. J. Sound Vib. 243(3), pp. 525-545 ( 2001)

41. Vaishya, M., Singh, R.: Sliding friction-induced non-linearity and parametric effects in gear dynamics. J. Sound Vib. 248(4), 671-694 (2001)

42. Xu, H., Kahraman, A., Anderson, N.E., Maddock, D.G.: Prediction of mechanical efficiency of parallel-axis gear pairs. ASME J. Mech. Des. 129, 58-68 (2007)

43. $\mathrm{Xu}, \mathrm{H}$. : Development of a generalized mechanical efficiency prediction methodology for gear pairs. PhD Dissertation, The Ohio State University, Columbus, Ohio (2005)

44. He, S., Cho, S., Singh, R.: Prediction of dynamic friction forces in spur gears using alternate sliding friction formulations. J. Sound Vib. 309, 843-851 (2008)

45. García-Vallejo, D., Mayo, J., Escalona, J.L., Domínguez, J.: Three-dimensional formulation of rigid-flexible multibody systems with flexible beam elements. Multibody Syst. Dyn. 20, 1-28 (2008)

46. Liu, C., Tian, Q., Hu, H.Y., García-Vallejo, D.: Simple formulations of imposing moments and evaluating joint reaction forces for rigid-flexible multibody systems. Nonlinear Dyn. 69, 127-147 (2012)

47. Shabana, A.A., Yakoub, R.Y.: Three-dimensional absolute nodal coordinate formulation for beam elements: theory. J. Mech. Des. 123, 606-613 (2001)

48. Yakoub, R.Y., Shabana, A.A.: Three dimensional absolute nodal coordinate formulation for beam elements: implementation and applications. J. Mech. Des. 123, 614-621 (2001)

49. He, S., Gunda, R., Singh, R.: Effect of sliding friction on the dynamics of spur gear pair with realistic time-varying stiffness. J. Sound Vib. 301, 927-949 (2007)

50. Weber, C.: The Deformation of Loaded Gears and the Effect on Their Load-carrying Capacity. 
Sponsored Research. British Dept. Sci. and Ind. Res. Report No.3., Germany (1949)

51. Cornell, R.W.: Compliance and stress sensitivity of spur gear teeth. ASME J. Mech. Des. 103, 447-459 (1981)

52. Attia, Y.: Deflection of spur gear teeth cut in thin rims. ASME paper 63-WA-14 (1963)

53. Baud, S., Velex, P.: Static and dynamic tooth loading in spur and helical geared systems-experiments and model validation. J. Mech. Des. 124, 334-346 (2002)

54. Sainsot, P., Velex, P., Duverger, O.: Contribution of gear body to tooth deflections a new bidimensional analytical formula. J. Mech. Des. 126, 748-752 (2004)

55. Wang, Y.: Dynamic modelling of flexible geared multibody system: A finite element approach. Ph.D. Thesis, City University of Hong Kong (1999)

56. Yang D.C.H., Sun, Z.S.: A rotary model for spur gear dynamics. ASME J. Mech., Trans. Aut. Des. 107, 529-535 (1985)

57. Chaari, F., Fakhfakh, T., Haddar, M.: Analytical investigation on the effect of gear teeth faults on the dynamic response of a planetary gear set. Noise \& Vibration Worldwide. 37, 9-15 (2006)

58. Chaari F., Baccar, W., Abbes, M.S., Haddar, M.: Effect of spalling or tooth breakage on gearmesh stiffness and dynamic response of a one-stage spur gear transmission. Eur. J. Mech. A/Solids 27, 691-705 (2008)

59. Chaari, F., Fakhfakh, T., Haddar, M.: Analytical modeling of spur gear tooth crack and influence on gear mesh stiffness. Eur. J. Mech. A/Solids 28, 461-468 (2009)

60. Wang, J., Zheng, J.H., Yang, A.: An analytical study of bifurcation and chaos in a spur gear pair with sliding friction. Procedia Engineering 31, 563-570 (2012)

61. He, S., Singh, R.: Dynamic transmission error prediction of helical gear pair under sliding friction using Floquet theory. J. Mech. Des. 130, 0526031-0526030 (2008)

62. Xu, H., Kahraman, A.: Prediction of friction-related power losses of hypoid gear pairs. Proc. Inst. Mech. Eng. Part K: J. Multibody Dyn. 221, 387-400 (2007)

63. Bathe, K.J.: Finite Element Procedures. Prentice Hall, New Jersey (1996)

64. Shabana, A.A.: Computational dynamics, 3rd edn. New York, USA: John Wiley \& Sons (2010)

65. Shabana, A.A.: Computational Continuum Mechanics. Cambridge University Press, Cambridge (2008)

66. Liu, C., Tian, Q., Hu, H.Y.: Dynamics of a large scale rigid-flexible multibody system composed of composite laminated plates. Multibody Syst. Dyn. 26, 283-305(2011)

67. Arnold, M., Brüls, O.: Convergence of the generalized-a scheme for constrained mechanical systems. Multibody Syst. Dyn. 18, 185-202 (2007)

68. Liu, C., Tian, Q., Hu, H.Y.: Dynamic analysis of membrane systems undergoing overall motions, large deformations and wrinkles via thin shell elements of ANCF. Comput. Methods Appl. Mech. Engrg. 258, 81-95 (2013)

69. Seo, J.H., Jung, I.H., Park, T.W., Chai, J.B.: Dynamic analysis of a multibody system including a very flexible beam element. JSME International Journal Series C. 48(2), 224-233 (2005) 